\title{
An overview of the Brazilian contributions to Green Analytical Chemistry
}

\author{
MARIANA R. GAMA ${ }^{1}$, WANESSA R. MELCHERT ${ }^{2}$, THIAGO R.L.C. PAIXÃO ${ }^{3}$ and FÁBIO R.P. ROCHA ${ }^{1}$ \\ ${ }^{1}$ Centro de Energia Nuclear na Agricultura, Universidade de São Paulo, \\ Avenida Centenário, 303, 13400-970 Piracicaba, SP, Brazil \\ ${ }^{2}$ Escola Superior de Agricultura "Luiz de Queiroz", Universidade de São Paulo, Caixa Postal 9, 13418-970 Piracicaba, SP, Brazil \\ ${ }^{3}$ Instituto de Química, Universidade de São Paulo, Av. Prof. Lineu Prestes, 748, 05508-900 São Paulo, SP, Brazil
}

Manuscript received on March 20, 2018; accepted for publication on April 17, 2018

\begin{abstract}
How to cite: GAMA MR, MELCHERT WR, PAIXÃO TRLC AND ROCHA FRP. 2019. An overview of the Brazilian contributions to Green Analytical Chemistry. An Acad Bras Cienc 91: e20180294. 10.1590/0001-3765201920180294.

Abstract: Green Analytical Chemistry (GAC) is a research field that seeks for more sustainable analytical approaches to minimize the toxicity and amounts of wastes without hindering the analytical performance. This is a trend in Analytical Chemistry worldwide and because of the diversity of innovations on this subject, Brazil stands out as the third in the list of the main contributors to GAC, with ca. $11.2 \%$ of the published articles. Significant innovations and interesting applications in several fields have been presented and Brazil is continuously moving from Chemistry to Green Chemistry also in the Analytical Chemistry field. Selected contributions for sample preparation, spectro- and electroanalysis, separation techniques, chemometrics, and also procedures for point-of-care measurements are critically reviewed.
\end{abstract}

Key words: environmental friendly analytical chemistry, green chemistry, miniaturization, microextractions, reagentless procedures.

\section{INTRODUCTION}

Green Chemistry is defined as the exploitation of techniques and methodologies aiming to reduce or eliminate the use of chemicals that are hazardous to human health or the environment and thus the amounts and toxicity of wastes (Anastas 1999). Nowadays, it is a well-established research area, which has focused mainly on improvements in organic synthesis (e.g. lower consumption of toxic solvents and minimization of by-products). The same principles have been applied to Analytical

$\overline{\text { Correspondence to: Fábio Rodrigo Piovezani Rocha }}$ e-mail: frprocha@cena.usp.br

ORCid: https://orcid.org/0000-0003-2517-6347

* Contribution to the centenary of the Brazilian Academy of Sciences.
Chemistry and the development of environmental friendly procedures is also a trend.

Several efforts have been made to reduce or eliminate the production of toxic wastes in chemical analysis without hindering the analytical performance. In this context, the term Green Analytical Chemistry (GAC) was coined to refer to the analytical strategies that generate lower waste amounts, less harmful residues or both (Armenta et al. 2008). Excellent discussions about the development of GAC and the involved strategies have been presented by authors worldwide (Armenta et al. 2008, Gałuszka et al. 2013, Turner 2013). The first attempt involves reagentless procedures (including direct analysis), but often this is not feasible and some sample treatment or 
analyte derivatization is required. Replacement of toxic chemicals, minimization of waste generation, recycling, and reuse of chemicals have been then exploited. Ultimately, waste needs to be suitably managed and treated. The strategies for GAC are often safer and cost-effective, by avoiding or diminishing the amounts of chemicals and by using mild reactional conditions. Moreover, the expenses involved in waste management and treatment are significantly lower.

Brazilian researchers have effectively contributed to GAC with new approaches and incremental developments on the several steps of chemical analysis. Indeed, a survey in the ISI Web of Science database revealed that Brazil is the third in the list of the highest contributors to GAC, with ca. $11.2 \%$ of the published articles (for comparison, contributions from Spain and USA correspond to 13.8 and $13.2 \%$, respectively). This tradition dates from the pioneering works of Fritz Feigl in the development of qualitative spot tests (Feigl 1955). Although assays often involved highly toxic chemicals, the proposal was a cornerstone in microanalysis as the determinations were carried out with only a few drops of sample and reagents. The proposal is still up-to-date and it has been also applied to quantitative analysis by different approaches (Luiz et al. 2013, Soares et al. 2017).

A diversity of terms has been indistinctly used in relation to GAC, including Environmentally Friendly Analytical Chemistry, Sustainable Analytical Chemistry, and Clean Analytical Methods. On the other hand, sometimes the green character is not highlighted in relevant contributions to the field. This aspect makes a literature survey about GAC difficult and hinders a comprehensive discussion about this issue. Thus, this overview aims a critical discussion of the main innovations aiming at GAC, with emphasis on the Brazilian contributions, including sample treatment (sample decomposition and analyte extraction) and clean-up, as well as analyte detection by molecular or atomic spectrometry, electroanalysis, separation techniques, and alternatives for pointof-care measurements. The inherent potential of flow analysis and chemometrics to achieve more environmental friendly procedures is also highlighted.

\section{SAMPLE PREPARATION}

Sample preparation is one of the most important steps in chemical analysis and its performance is often decisive for obtaining reliable results. Classical methods typically require relatively high amounts of chemicals (e.g. solvents and concentrated acids) so that waste generation is often higher than in any other analytical step. Sometimes, sample preparation also demands high energy amount, such as in time-consuming processes carried out at high temperatures under convective heating. However, instrumental advances and new chemical approaches have yielded more environmental friendly processes for sample preparation, either aiming at sample decomposition or analyte extraction. Critical reviews on greener strategies for sample preparation (Rocha et al. 2009, 2013) or specifically aiming at sample digestion (Bizzi et al. 2017) highlighted the impressive contributions of Brazilian researchers to the field.

\section{SAMPLE DECOMPOSITION}

Except for some analytical techniques that allow direct analysis of solid samples, such as X-ray spectrometry, electrothermal atomic absorption spectrometry, laser ablation-ICP-MS, and laserinduced breakdown spectrometry (LIBS), sample decomposition is required either for analyte solubilization, elimination of organic matter, or both. Moreover, sample solubilization is often needed for matrix matching or analyte preconcentration. Evolution of wet digestion of organic samples has sought for higher efficiency (i.e. low residual carbon contents, RCC) simultaneously with the 
minimization of reagent amounts (Bizzi et al. 2017). In this sense, wet digestions with relatively large amounts of acids (or mixture of acids) in open vessels have been replaced by microwave (MW)-assisted acid digestions in closed vessels, which typically require lower amounts of acids. In this way, organic samples can be digested essentially with nitric acid (often jointly with $\mathrm{H}_{2} \mathrm{O}_{2}$ ), as the reactivity of $\mathrm{HNO}_{3}$ substantially increases at the high temperatures provided by the high pressures achieved in closed vessels. Use of more toxic and harmful reagents (e.g. perchloric acid) is then avoided. In addition to greener procedures, minimization of reagent amounts contributes to diminish blank values, risks of sample contamination, and costs, also yielding sample digests more compatible with most instrumental techniques (e.g. ICPs, because of low residual acidity). Brazilian researchers have notably contributed with greener approaches for sample decomposition, including digestions in micro-flasks, use of dilute instead of concentrated acids, and MW-assisted combustion.

For analytical techniques that require low sample volumes (e.g. ETAAS and some electrochemical ones), green sample decomposition can be achieved by diminishing proportionally the sample mass and acid volumes. This approach was proposed by Sperling (1984) for decomposition of $5 \mathrm{mg}$ of biological materials aiming at $\mathrm{Cd}$ determination by GFAAS with a 100 -fold reduction of acid amount consumed and waste generated. This strategy was also investigated for digestion of (i) hair samples (10 mg) with $150 \mu \mathrm{L} \mathrm{HNO}_{3}$ plus 50 $\mu \mathrm{L} \mathrm{H}_{2} \mathrm{SO}_{4}$ aiming at As determination by hydride generation atomic absorption spectrometry (Flores et al. 2001) and (ii) medicinal plants (5 mg) with $200 \mu \mathrm{L} \mathrm{HNO}_{3}$ plus $150 \mu \mathrm{L}$ of $30 \% \mathrm{H}_{2} \mathrm{O}_{2}$ aiming at $\mathrm{Cd}$ determination by thermospray flame furnace atomic absorption spectrometry (Brancalion and Arruda 2005). Sample treatment was carried out under MW-assisted heating for $35 \mathrm{~min}$, after reaction for $30 \mathrm{~min}$ at ambient temperature (Flores et al. 2001) or for $4 \mathrm{~min}$ after $10 \mathrm{~min}$ at ambient temperature (Brancalion and Arruda 2005). In spite of these efficient decompositions, the mild experimental conditions may increase the digestion times and RCC for complex samples and low sample masses may be a drawback because of the sample heterogeneity. On the other hand, the approach is safe, inexpensive, and minimizes risks of sample contamination.

Araújo et al. (2002) demonstrated that efficient MW-assisted digestion of plant materials could be accomplished with dilute $\mathrm{HNO}_{3}$ (e.g. $2 \mathrm{~mol} \mathrm{~L}^{-1}$ ) plus $\mathrm{H}_{2} \mathrm{O}_{2}$ in closed vessels. Aiming at determination of several elements by ICP OES, RCC were lower than $11.3 \%$ and not significantly dependent on $\mathrm{HNO}_{3}$ concentration from 2.0 to $7.0 \mathrm{~mol} \mathrm{~L}^{-1}$. Moreover, only $0.8 \mathrm{mmol}$ of $\mathrm{HNO}_{3}$ was consumed for digestion of $250 \mathrm{mg}$ of sample. Besides acting as auxiliary oxidant, hydrogen peroxide also takes part of $\mathrm{HNO}_{3}$ regeneration inside the vessel, which encompass: (i) generation of $\mathrm{NO}$ by oxidation of organic matter by dilute $\mathrm{HNO}_{3}$; (ii) oxidation of $\mathrm{NO}$ by oxygen in the gas phase, and (iii) $\mathrm{NO}_{2}$ absorption by the solution to produce $\mathrm{HNO}_{3}$ (Bizzi et al. 2011). Thus, the oxygen in the gas phase (either directly introduced or generated by thermal decomposition of $\mathrm{H}_{2} \mathrm{O}_{2}$ ) and the temperature gradient between liquid and gas phases (inherent to MW-assisted heating) play essential roles in the process. Successful applications of digestion with dilute acids to a diversity of samples (e.g. animal fat, soybeans, and whole milk) were recently reviewed (Bizzi et al. 2017), thus demonstrating the feasibility of this greener approach for sample preparation.

Sample digestion with dilute acids can be improved by exploiting the synergistic effect of MW-assisted heating and UV irradiation, which yields highly reactive species (e.g. radicals). On the other hand, the limitations of UV-assisted digestions for solid samples (e.g. light scattering) can be circumvented by the MW-assisted process. 
The strategy became feasible after the advent of electrodeless discharge lamps (usually based on $\mathrm{Cd}$ or $\mathrm{Hg}$ emissions) that are activated by MW, thus avoiding the need for electrical connections. Brazilian researchers have demonstrated the applicability of the process to a diversity of samples (Bizzi et al. 2017), including some hard to digest by conventional approaches, even with concentrated acids. This can be illustrated by the effective digestion of crude oils aiming at determination of rare earth elements by ICP-MS. Up to $500 \mathrm{mg}$ of sample was effectively digested in $40 \mathrm{~min}(\mathrm{RCC}<$ $130 \mathrm{mg} \mathrm{C} \mathrm{g}^{-1}$ ) by using $10 \mathrm{~mL}$ of $4 \mathrm{~mol} \mathrm{~L}^{-1} \mathrm{HNO}_{3}$ plus $4 \mathrm{~mol} \mathrm{~L}^{-1} \mathrm{H}_{2} \mathrm{O}_{2}$ (Pereira et al. 2013a).

Some characteristics of sample digestion in micro-flasks and by dilute acids were combined in the acid-vapor partial digestion (Araújo et al. 2000). Micro-flasks with a sample suspended in a suitable medium (e.g. water or auxiliary oxidants, such as $\mathrm{H}_{2} \mathrm{O}_{2}$ or $\mathrm{NaOCl}$ plus $\mathrm{H}_{2} \mathrm{O}_{2}$ ) are placed in contact with acid vapors produced by MWassisted heating of concentrated $\mathrm{HNO}_{3}$. Results for cobalt and iron obtained by ICP OES agreed with the certified values after digestion for 10 or 60 min, respectively. This strategy also allows purification of the acid by distillation and reduces its consumption (2.5 $\mathrm{mL}$ of $\mathrm{HNO}_{3}$ per sample), although in a lower extend than the previously described approaches. For example, equivalent amounts of ca. 0.2 and $0.3 \mathrm{~mL}$ concentrated $\mathrm{HNO}_{3}$ were consumed in the digestion of similar samples in micro-flasks and by dilute acids, respectively, whereas the classical nitro-perchloric digestion in open vessels consumed $7.5 \mathrm{~mL}$ of concentrated $\mathrm{HNO}_{3}$ (plus $2.0 \mathrm{~mL}$ of $\mathrm{HClO}_{4}$ ) per sample (Krug et al. 1977).

The previously discussed approaches are more environmental friendly because of the significant minimization of acid amount and the use of less corrosive dilute solutions. Although highly desirable in the scope of GAC, replacement of toxic reagents used in sample decomposition is hard to achieve because a highly oxidative medium is often needed. In this sense, advanced oxidative processes involving generation of highly reactive radicals (e.g. from UV irradiation of some precursor species) have been successfully exploited. An ingenious approach was the in situ photocatalytic decomposition of organic matter in a $\mathrm{TiO}_{2}$-modified gold electrode under irradiation by an UV-LED before voltammetric measurements of metal ions (Daniel and Gutz 2007). The in situ sample treatment is also advantageous because only the sample amount required for detection is decomposed, thus avoiding the unnecessary waste generation. Photo-oxidative processes have been also widely exploited for analyte conversions, as exemplified by phosphorus fractionation in cereals (Rocha and Rocha 2013). Organic phosphorus was converted to phosphate by sulfate and hydroxyl radicals produced from UV irradiation of a persulfate solution in a flow system. The reproducible timing and reaction conditions allowed the analytical exploitation of the process even with a conversion rate estimated at $48 \%$. In this way, use of concentrated acids was avoided and the reagent consumption was minimized to less than $0.8 \mathrm{mg} \mathrm{K}_{2} \mathrm{~S}_{2} \mathrm{O}_{8}$ per determination. However, as previously mentioned, exploitation of UV-assisted decomposition of solid samples may be hindered by light scattering.

Microwave-induced combustion (MIC) involves elimination of organic matter, analyte volatilization, and absorption on dilute acid or alkaline solutions or even water, thus making the approach more environmental friendly. Reflux of this solution has been exploited to improve analyte absorption or to complete the sample digestion. The process has been carried out mainly in closed vessels (Moraes et al. 2007) pressurized with oxygen (ca. 20 bar is enough for combustion of 500 mg sample), but also in open vessels by exploiting focused MW equipment (Mesko et al. 2010). These strategies show characteristics of sample digestion 
on closed and open vessels, such as lower risks of analyte losses and treatment of higher sample amounts (e.g. 3.0 g), respectively. MIC has been an alternative for samples difficult to decompose under conventional MW-assisted acid digestions, especially for those with high carbon content (Bizzi et al. 2017).

Replacement of toxic chemicals was also demonstrated by using dilute $\mathrm{NaOH}$ (instead of $\mathrm{HF}$ ) for solubilization of $\mathrm{Si}$ in plant digests (Barros et al. 2016). The proposed procedure involved: (i) $\mathrm{MW}$-assisted digestion with dilute $\mathrm{HNO}_{3}$ plus $\mathrm{H}_{2} \mathrm{O}_{2}$; (ii) alkalinization of the digest followed by MW-assisted Si dissolution; and (iii) neutralization of the solution before measurements by ICP OES to avoid damages to the quartz torch. Sample decomposition with dilute acids at the first step was also decisive to minimize the salt content in the digests, which could hinder measurements by ICP OES.

Other greener alternative for sample preparation is the analyte extraction from the sample instead of the matrix mineralization. This typically requires mild experimental conditions and lower acid concentrations. These characteristics can be illustrated by the extraction of $\mathrm{Ca}, \mathrm{Mg}, \mathrm{Mn}$, and $\mathrm{Zn}$ from vegetables (ca. $300 \mathrm{mg}$ sample) by using 15 $\mathrm{mL}$ of $0.14 \mathrm{~mol} \mathrm{~L}^{-1} \mathrm{HNO}_{3}$ and sonication for $10 \mathrm{~min}$ (Nascentes et al. 2001). Typically, extraction is fast under sonication, but strict control of experimental conditions (e.g. particle size and effective power of the US bath) is needed to achieve reliable results. Extractions can be incomplete for some samples and analytes, depending on the chemical form and linkage to the sample matrix. The extracts are usually suitable for atomic spectrometric detection but not for techniques susceptible to the effect of organic matter, which can be bonded to metal ions (e.g. UV-vis spectrophotometry and some electroanalytical techniques). Potentialities, limitations and applications of this approach were highlighted (Santos Jr et al. 2006).

\section{EXTRACTION AND CLEAN-UP}

Sample clean-up and analyte extraction are frequently needed in chemical analysis and usually generate high amounts of toxic wastes. Greener strategies have exploited miniaturization or replacement of toxic solvents, and even reagentfree methodologies have been proposed (Filippou et al. 2017, Plotka-Wasylka et al. 2017). In this sense, solid-phase microextraction (SPME), stir bar sorptive extraction (SBSE), microextraction by packed sorbent (MEPS), liquid-phase microextraction (LPME), and pipette tip-based micro-solid phase extraction (PT- $\mu \mathrm{SPE})$ stand out as discussed next. Other promising green approaches involve aqueous two-phase systems (ATPS) or extraction by emulsion breaking. A schematic representation of SPME, SBSE, MEPS, and PT- $\mu$ SPE approach is shown in Figure 1.

\section{Solid-phase microextraction}

SPME (Fig. 1a) is one of the most popular green approach for sample preparation, which provides a convenient alternative to most conventional techniques. In SPME, analytes can be desorbed thermally or by using organic solvents. The former is the greener choice, as it avoids the use of solvents, but a low amount of eluent (typically in the microliter range) is often required for chemical desorption, still classifying the SPME as a green approach. In addition to these GAC advantages, the configuration of the SPME device reduces the need for high sample volumes and thus the effluent volumes (Souza-Silva et al. 2013).

Since the inception of SPME by Arthur and Pawliszyn (1990), several workgroups have consolidated this research topic, especially aiming at isolation of compounds from complex matrices (Soares et al. 2015, Andrade and Lanças 2017, PiriMoghadam et al. 2017). Although it can be also employed for non-volatile analytes using a directimmersion configuration, SPME is mainly applied 

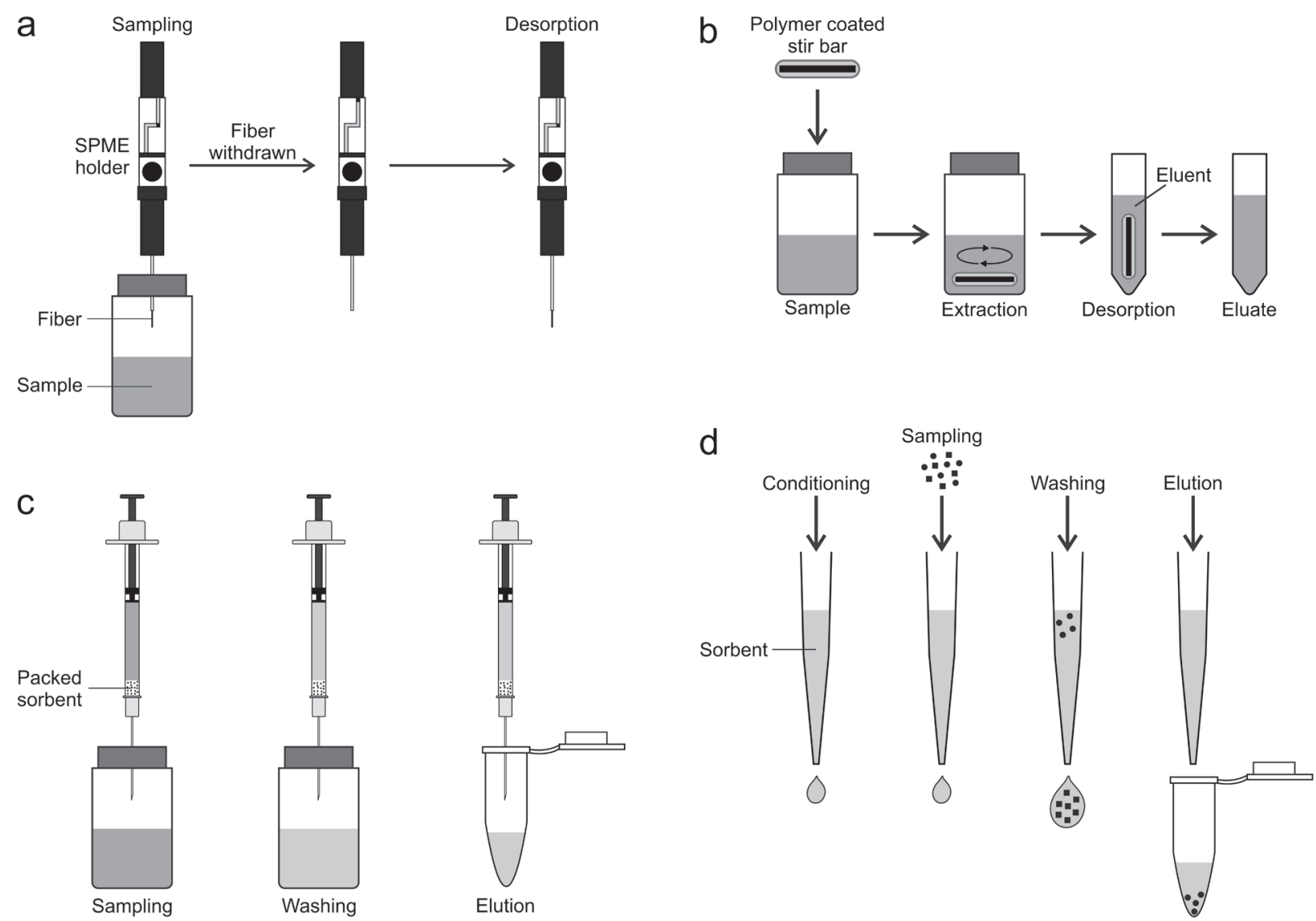

Figure 1 - Schematic representation of approaches for solid-phase green sample preparation: (a) SPME, (b) SBSE, (c) MEPS and (d) PT- $\mu$ SPE.

to volatile compounds (headspace mode) from highly complex matrices, such as honey (Rivellino et al. 2013), fungus for fermentation cultures (Schacker et al. 2017), and even living biological systems (Brunetti et al. 2015). In an interesting approach, the extraction of volatile biomarkers for early diagnosis of fungus disease in trees exploited SPME, with a significant impact on agronomic productivity of eucalyptus trees (Hantao et al. 2013).

Trends in SPME are the development of new fiber support formats and synthesis of more selective coatings (Augusto et al. 2010, Piri-Moghadan et al. 2017). Generally, the extraction process is more efficient when high selective sorbents are used, as extraction of potentially interfering species is minimized (Clark et al. 2018). Then, selective sorbents can require lower sample volumes, thus diminishing waste generation. In this sense, ionic liquids (Toledo et al. 2014, Merib et al. 2016) and molecularly imprinted coatings (Sarafraz-Yazdi and Razavi 2015, Souza et al. 2016) have increased the analyte isolation by SPME fibers. Restricted access materials (Chaves et al. 2011) and immunosorbents (Queiroz et al. 2007) have also been investigated as SPME coatings with improved selectivity. In addition, the reuse of the SPME fiber avoids both early replacement and disposal.

\section{Stir bar sorptive extraction}

In SBSE (Fig. 1b), introduced by Baltussen et al. (1999), a polymer-coated magnetic bar retains the analyte by the direct contact with the aqueous sample. Either thermal or chemical desorption of 
the compounds is directly performed in a separation system (Lanças et al. 2009).

The green aspect of SBSE resides in the solventless desorption before $\mathrm{GC}$ analysis or the lower volume of eluent when chemical desorption is chosen, generally prior to LC analysis. For instance, Pereira et al. (2014a) employed SBSE with chemical desorption for alkaloids isolation from passion fruit samples. Desorption required only $150 \mu \mathrm{L}$ of organic solvent, which is $90 \%$ lower in comparison to the classical solid phase extraction (SPE).

SBSE can overcome some limitations of SPME, such as long time to achieve equilibrium conditions (Cassiano et al. 2014). Other advantages include improved selectivity and wide application for several matrices. However, low recoveries were observed for complex matrices. For example, Freitas-Lima et al. (2015) reported recoveries of 10 and $60 \%$ of an anticonvulsant drug spiked to plasma by SBSE and classical SPE, respectively, and both procedures required the same eluent volume.

\section{Microextraction by packed sorbent}

As illustrated in Fig. 1c, MEPS resulted from the miniaturization of classic SPE. Only 1-4 mg of sorbent is inserted into a syringe (100-250 $\mu \mathrm{L})$. Low amounts of sample, usually from 20 to $500 \mu \mathrm{L}$, are drawn through the syringe by an autosampler or manually. Removal of potential interfering species is performed by a low volume of a washing solution (e.g. $50 \mu \mathrm{L}$ ) and analytes are further removed with 20-50 $\mu \mathrm{L}$ of eluent. Thus, MEPS is a fast, simple, and inexpensive GAC technique, with reduced sample, solvent, and sorbent amounts in all steps (Abdel-Rehim 2004, Mahdi-Moein et al. 2015).

MEPS has been mainly focused on sample preparation prior to chromatographic bioanalysis, such as for drug isolation from plasma samples (Ortega et al. 2017, Viana et al. 2014) and pesticides in food matrices (Fumes et al. 2015). Interesting developments refer to the synthesis of novel sorbents, such as carbon nanostructured packings (Fumes and Lanças 2017), hybrid materials (Souza et al. 2015), and molecularly imprinted materials (Andrade et al. 2014).

Similarly, sample preparation by PT- $\mu$ SPE (Fig. 1d) involves a low amount of sorbent packed into a pipette tip, inside which all extraction steps are performed (Bordin et al. 2016). Amounts of both packing sorbent and solvent are reduced and the same pipette tip may be reused for 50 to 100-times, depending on the analytes and sample matrices (Queiroz 2011). As observed for MEPS, PT- $\mu$ SPE is useful for analyte recovery from biological samples, because the high selectivity compensates the reduced availability of biosamples (Silva et al. 2016a)

Analyte isolation and enrichment by classical and miniaturized SPE are compared in Table I (Kabir et al. 2017, Mahdi-Moein et al. 2014) and the reduction in sample and eluent volumes by the more recent strategies is notable. Although listed as a GAC technique, SBSE may spend large volumes of solvents for desorption, sometimes comparable to classic SPE, and then its green aspect can be questioned.

\section{Liquid-phase microextraction}

LPME is a simple and inexpensive sample pretreatment approach involving LLE with minimized solvent consumption. Although LPME involves different modalities, as a rule, less than $10 \mu \mathrm{L}$ of a water-immiscible solvent (acceptor phase) is used to extract the analytes from the aqueous sample (donor phase). LPME is suitable for sample preparation in forensic analysis and biological applications (Nerin 2016), in which the analytes are usually extracted from a limited amount of sample. In this sense, LPME has been successfully applied to several biological samples prior to chromatographic analysis, including breast 
human milk (Silveira et al. 2016), hair (Pego et al. 2017), and urine (De Araújo et al. 2015) yielding high analyte recoveries. Decanol, dihexyl ether or dodecane were employed as acceptor phase and their minimized consumption demonstrated the advantage of LPME to GAC.

In single-drop microextraction (SDME), microliter amounts (from 1 to $8 \mu \mathrm{L}$ ) of an extracting solvent are suspended in a syringeneedle and directly immersed in the sample or in the headspace (Pinto and Pedroso 2015). Multiresidue determination of pesticides (Dos Anjos and De Andrade 2014), as well as the determination of $\mathrm{Cd}$ in vegetable oils (Almeida et al. 2015) demonstrated the successful use of SDME for sample preparation, with a diminution of solvent consumption from several $\mathrm{mL}$ to few $\mu \mathrm{L}$.

Hollow-fiber LPME (HF-LPME) is another advance of the liquid-phase extraction, based on impregnation of a hydrophobic porous hollow fiber with an organic solvent, whereas the lumen is filled with a few microliters of an acceptor phase. The significant reduction of acceptor volume is especially important in relation to the use of toxic solvents, such as octane, chloroform, and benzene. HF-LPME has been mainly exploited for isolation of analytes from biological samples, such as human metabolites (Paiva et al. 2015, Fonseca and Bonato 2013).

\section{Aqueous two-phase systems}

ATPS is a modality of LLE, in which the systems are essentially composed by water and other nontoxic components, as polymers or macromolecules. Some ATPS comprise ionic liquids and short-chain alcohols, as well as ionic and non-ionic surfactants (Iqbal et al. 2016). Salt-rich and polymer-rich phases are formed under suitable conditions of temperature, $\mathrm{pH}$, and salt amounts (Grilo et al. 2016). As the relative volumes can be varied and strategies can be adopted to increase analyte
TABLE I

Some characteristics of sample preparation techniques. Adapted from Kabir et al. 2017 and Mahdi-Moein et al. 2014.

\begin{tabular}{lccc}
\hline Method & $\begin{array}{c}\text { Sample } \\
\text { volume }(\mathbf{m L})\end{array}$ & $\begin{array}{c}\text { Elution } \\
\text { volume }(\mathbf{m L})\end{array}$ & Reuse \\
\hline Classical SPE & $1.0-2.0$ & $1.0-6.0$ & $\begin{array}{c}\text { Single } \\
\text { use }\end{array}$ \\
SPME & $0.5-20$ & $<0.5$ & $50-100$ \\
SBSE & $1-100$ & $<1.0$ & 100 \\
MEPS & $0.02-0.5$ & $0.02-0.05$ & $40-100$ \\
PT- $\mu$ SPE & $0.05-0.5$ & $0.2-0.5$ & $50-100$ \\
\hline
\end{tabular}

partition (e.g. addition of a suitable ligand for extraction of metal ions), ATPS is a powerful tool for analyte separation and enrichment.

By avoiding toxic organic solvents and using biodegradable and biocompatible components, ATPS is regarded as environmentally safe, with some advantages over conventional LLE such as easy application, low cost, and possibility to recycle components (Silva and Loh 2006). However, the wastes may not be completely environmentally safe because of the large amounts of additives required for formation of an ATPS. Applications of ATPS for isolation and enrichment of several chemical species include organic pollutants (Rodrigues et al. 2010), metal ions (Rodrigues et al. 2012), and biotechnological applications, as extraction and purification of proteins, enzymes and other biomolecules (Silva and Loh 2006).

Use of smart-polymers can improve the green aspects of ATPS. In this approach, a single polymer (e.g. those formed by copolymerization of ethylene oxide and propylene oxide groups) forms a twophase system in water (Johansson et al. 1999), and the separation is performed by the collapse of the polymer structure, driven by alterations in $\mathrm{pH}$ or ionic strength, for example (Zaslavsky 1995). The polymer can be recycled, thus reducing waste generation and costs. 


\section{Extraction by emulsion breaking}

Because of their water-immiscibility, sample preparation of oil samples generally requires organic solvents. Extraction induced by emulsion breaking is a greener alternative to isolate the analytes from these samples, by adding a substance to form water-oil emulsions, which are further broken by centrifugation or sonication. Analytes often remain in the aqueous phase, thus being available for direct determination usually by atomic spectrometry. This approach has replaced ordinary methods that involve large volumes of toxic solvents for trace metal ion extractions (Dantas et al. 2001, Pereira et al. 2013b).

Preparation of petroleum and derivatives samples (e.g. crude oil and gasoline) as well as biodiesel by emulsion breaking has been widely discussed (Trevelin et al. 2016, Pereira et al. 2014b, Robaina et al. 2016). Recently, Vicentino and Cassella (2017) proposed the Hg isolation from gasoline samples by extraction induced by microemulsion breaking. The method required less than $2 \mathrm{~mL}$ of solvents, i.e. $1.2 \mathrm{~mL}$ of n-propanol, $0.1 \mathrm{~mL}$ of $\mathrm{HCl}$ solution, and $0.3 \mathrm{~mL}$ of water for the phase separation, compared to several $\mathrm{mL}$ of organic solvent employed on classical LLE. Recovery values were in the range of $88-109 \%$.

\section{MOLECULAR SPECTROMETRY}

Molecular spectrometry typically involves chemical derivatization to improve sensitivity, selectivity or both. Moreover, chemical derivatization allows expanding application to non-absorbing species or to those that do not exhibit luminescence. The most significant exception refers to direct sample analysis by infrared spectrometry, which usually involves multivariate data treatment. Several relevant applications have been presented, including determination of biodiesel in blends with diesel and detection of adulteration by vegetable oils (Pimentel et al. 2006) and the non-invasive estimation of quality indicators in fruits with a handheld NIR spectrometer (Marques et al. 2016).

Chemical derivatization may be timeconsuming and generate toxic wastes from the reagents and solvents required. Reagentless procedures are scarce and often involve less complex samples because of the limitations in selectivity. Some examples include the determination of species of pharmaceutical interest by UV-vis spectrophotometry often in the derivative mode (Ojeda and Rojas 2004). Aiming at avoiding the use of reagents, physicochemical properties less usual in analytical procedures have been exploited. For instance, increase of the temperature provided by the heat of dilution of ethanol in water was indirectly measured by an infrared camera and exploited for determination of alcoholic content of beverages (Oliveira et al. 2017). This enthalpimetric procedure also significantly diminished the energy demand in comparison with usual alternatives (e.g. GC). Other ingenious approaches for reagentless procedures are described in the section of this overview devoted to flow analysis.

Replacement of toxic reagents, minimization of waste amounts and, in a lower extent, recycling and reuse of chemicals are the alternatives to achieve GAC when chemical derivatization is involved. Some illustrative contributions to achieve these goals are discussed next.

Replacement of toxic chemicals can be achieved only in specific circumstances. Photochemical conversions are a powerful tool for greener chemical derivatizations. UV radiation is exploited to modify the structure of the analyte, e.g. by breaking chemical bonds and inducing cyclization reactions and rearrangements (Zweig 1973), thus forming species with higher molar absorptivity, higher luminescence quantum yield or both. This can be exemplified by the photochemical derivatization of the antidepressant amitriptyline under UV irradiation of the samples (60 $\mathrm{min}$ ) in a medium of dilute acid $\left(0.027 \mathrm{~mol} \mathrm{~L}^{-1} \mathrm{HCl}\right)$ to form 
highly fluorescent species (Osorio et al. 2014). The approach avoided the toxic reagents or solvents typically used in fluorimetric or HPLC methods but the mercury lamps used as UV sources need to be properly handled and disposed. Another ingenious alternative involves electrochemical derivatization of the analyte, as demonstrated in the spectroelectrochemical determination of the antihistaminic promethazine (Daniel and Gutz 2003). The method was based on in situ detection of a colored cationic radical formed during electroxidation of the analyte in dilute acid medium, $0.1 \mathrm{~mol} \mathrm{~L}^{-1} \mathrm{H}_{2} \mathrm{SO}_{4}$ at a gold electrode modified with $\mathrm{TiO}_{2}$. The approach avoided interferences by other electroactive species observed in direct amperometric measurements.

Also aiming to avoid toxic reagents, an environmental friendly procedure was proposed for determination of melamine as an adulterant of protein content in milk (Nascimento et al. 2015). Sample clean-up involved protein precipitation with dilute trichloroacetic acid and fat removal by cloud point extraction with Triton X-114. The surfactant was also used as fluorophore and the fluorescence quenching by the analyte was exploited to determine as low as $320 \mu \mathrm{g}$ melamine $/ 100 \mathrm{~g}$ of milk.

Because of the capability to process low amounts of sample, microanalytical techniques are inherently suitable for GAC. Even when toxic chemicals are needed, their amounts may be minimized in such a way that the procedures can be classified as environmental friendly. For instance, a successful approach was proposed for fast determination of adulterants in milk (whey, synthetic milk, synthetic urine, urea, and hydrogen peroxide) with standard errors of prediction of $2.33,0.06,0.41,0.30$, and $0.014 \mathrm{~g} \mathrm{~L}^{-1}$, respectively, based on attenuated total reflectance mid-infrared microspectroscopy (Santos et al. 2013). As the determination required only $1 \mu \mathrm{L}$ of a treated sample, the volume of chloroform required for fat removal (in equal volumes to the sample) was minimized. This characteristic is also intrinsic to the quantitative spot tests involving spectrophotometric detection by diffuse reflectance (Luiz et al. 2013) or by exploiting digital images (Soares et al. 2017). These applications refer to the determination of furosemide in urine aiming at detection of doping (Luiz et al. 2013) and iodine value to evaluate the oxidative stability of biodiesel (Soares et al. 2017) by using only micrograms of reagents.

Low reagent consumption is also inherent to (microfluidic) paper-based analytical devices (PADs), which often exploit colorimetric detection. As these devices hold several advantages such as low cost and suitability for point-of-care testing, a notable development has been recently observed. Operational aspects as well as analytical and bioanalytical applications of these devices were discussed in a critical review (Morbioli et al. 2017). Interesting applications include enzymatic assays for detection of sarcosine in urine aiming at detection of prostate cancer (Nascimento et al. 2016) and glucose and uric acid in serum, which would be useful for detection of diseases such as diabetes and gout (Gabriel et al. 2016). The microfluidic devices were designed by modification of the paper by wax printing or with chitosan, respectively. Although some relatively toxic reagents were required, the environmental impact is minimized by using from 1-5 $\mu \mathrm{L}$ of solution and impregnation of the reagent on the paper support.

\section{ATOMIC SPECTROMETRY}

Apart from the use of chemical modifiers and the gases produced during atomization in some techniques, the main source of waste generation in atomic spectrometry is the sample preparation because most of the approaches require solid samples to be converted to solutions. However, as previously discussed, there are several alternatives for greener sample decomposition and spectrometric techniques usually demands 
low volumes of sample digests. On the other hand, some spectrometric techniques are suitable for direct solid sample analysis and thus are inherently greener approaches by avoiding toxic or corrosive reagents and generating less waste. Techniques involving sample nebulization are typically characterized by low efficiency and thus large production of wastes. Microinjection of sample aliquots is an alternative to circumvent this drawback without hindering analytical performance (Silva et al. 2010). Other question to concern in relation to atomic spectrometry is the need for high power suppliers as lower energy consumption is also a goal of GAC.

Solid sampling graphite furnace atomic absorption spectrometry (SS-GFAAS) has advantages in the development of clean procedures because it requires low sample amounts and enables a thermal pretreatment inside the atomizer. For example, aiming at toxicological and environmental investigations, determination of $\mathrm{Cd}$ and $\mathrm{Pb}$ in hair was carried out with only $80 \mu \mathrm{g}$ of sample weighed directly on a boat type platform and requiring only $10 \mu \mathrm{L}$ of a chemical modifier $\left(5 \mu \mathrm{g}\right.$ of $\mathrm{Pd}\left(\mathrm{NO}_{3}\right)_{2}$ and $3 \mu \mathrm{g}$ of $\mathrm{Mg}\left(\mathrm{NO}_{3}\right)$ (Nomura and Oliveira 2010). Calibration may be performed with aqueous solutions, with responses similar to those obtained with a certified reference material. The limits of detection were in the order of $\mathrm{ng} \mathrm{g}^{-1}$ because sample dilution inherent to the decomposition step was avoided. Absence of the sample digestion step also minimizes sample handling as well as risks of contamination and loss of the analyte. Another interesting application of SS-GFAAS is the analysis of refractory samples, as demonstrated by the determination of $\mathrm{Co}, \mathrm{Cr}$, and $\mathrm{Mn}$ in Portland cement (Intima et al. 2009). Up to $200 \mu \mathrm{g}$ sample and only $10 \mu \mathrm{L}$ of a mixture $\mathrm{Na}_{2} \mathrm{CO}_{3}+\mathrm{ZnO}+$ Triton $\mathrm{X}-100$ were heated at $800{ }^{\circ} \mathrm{C}$ for $20 \mathrm{~s}$. The mould was dissolved in 10 $\mu \mathrm{L}$ of $0.1 \% \mathrm{~m} / \mathrm{v} \mathrm{HNO}_{3}$. All steps occurred on the boat-type graphite platform avoiding sample contamination and saving time, with advantages in relation to the classical fusion procedure, which requires large amounts of dilute acids $(20 \mathrm{~mL}$ of $\left.0.1 \% \mathrm{~m} / \mathrm{v} \mathrm{HNO}_{3}\right)$ and sample $(0.5 \mathrm{~g})$.

In situ sample pretreatment was also exploited in the decomposition of the organic matrix of biodiesel in a tungsten coil atomizer aiming at determination of $\mathrm{Na}, \mathrm{K}, \mathrm{Cr}$, and $\mathrm{V}$ by atomic emission spectrometry (Dancsak et al. 2014). Biodiesel samples $(10 \mu \mathrm{L})$ were diluted in methanol or ethanol (instead of kerosene and xylene commonly employed in the biodiesel analyses) and introduced directly into the atomizer using a micropipette. The heating cycle demanded less than $150 \mathrm{~s}$, including sample pyrolysis. Tungsten coils also stands out by the lower energy demand in comparison to graphite atomizers because of lower mass and specific heat, which makes these devices very attractive for GAC (Rocha et al. 2009). Detection limits in the $\mu \mathrm{g} \mathrm{L}^{-1}$ range were estimated and calibration with organometallic standards was not required.

Slurry sampling is advantageous in the development of clean procedures, mainly by decreasing the consumption of concentrated acids, as well as the sample preparation time. This approach has been successfully exploited in GFAAS (Souza et al. 2013), FAAS (Amorim et al. 2017), ICP OES (Scheffler et al. 2014, Limbeck et al. 2017), ICP-MS (Tai et al. 2016) and total reflection $\mathrm{X}$-ray fluorescence (Resende and Nascentes 2016). Moreover, antimony determination in airborne particulate matter was the pioneer work in the application of slurry sampling with hydride generation quartz tube atomic absorption spectrometry (Ferreira et al. 2011). Calibration was performed with aqueous solutions (0.2-5.0 $\mu \mathrm{g} \mathrm{L}^{-1}$ $\mathrm{Sb}(\mathrm{III})$ ) and precision was estimated at $6.2 \%$.

Another green alternative for sample preparation in atomic spectrometry is the microemulsion technique, which presents advantages due to stability, low viscosity, and 
optical transparency. This approach was evaluated for $\mathrm{Ca}, \mathrm{K}, \mathrm{Mg}, \mathrm{Na}, \mathrm{P}$, and $\mathrm{S}$ determination in biodiesel by ICP OES with axial configuration and argon-oxygen plasma (Amais et al. 2011). Sample microemulsions were prepared using dilute nitric acid, Triton X-100, and n-propanol in contrast to conventional procedures that consume toxic organic reagents. By using mineral oil for preparing calibration solutions, correlation coefficients were better than 0.99 and coefficients of variation were within 1.5 and $6.8 \%$. Recoveries were estimated from 103.3 to $117.5,93.5$ to 113.5 , 76.3 to 92.5 , and 88.3 to $116.1 \%$ for $\mathrm{Ca}, \mathrm{Mg}, \mathrm{P}$, and $\mathrm{S}$ determinations, respectively.

Direct analysis of solids by X-ray fluorescence spectrometry is usual, often without or with minimal sample preparation. Applications include analysis of biological and geological samples, metal alloys, atmospheric particulate, ceramic, and polymeric materials (Garrigues and de la Guardia 2013). Portable systems are available for point-ofcare measurements. A recent application involved classification of nail polish samples based on $\mathrm{Ca}$ and Ti amounts (Shimamoto et al. 2013). A filter paper was used as surface support and samples were irradiated for $20 \mathrm{~s}$ with data processing by principal component analysis (PCA), without requiring sample preparation or using of chemicals.

In situ analysis of macro-, micronutrients, and $\mathrm{Si}$ in sugarcane leaves can be carried out by energy-dispersive X-ray fluorescence spectrometry (EDXRF) and laser-induced breakdown spectroscopy (LIBS) (Guerra et al. 2015). Leaves were washed, dried, cut, pressed between two paper disks, and submitted to the spectroscopic measurements. The collimated X-ray spot size $(5 \mathrm{~mm})$ was irradiated for $50 \mathrm{~s}$ while for LIBS measurements the spot size was $750 \mu \mathrm{m}$ with 48 accumulated laser pulses per line in each leaf fragment. It was estimated that 15 leaf fragments were enough to represent the whole leaf. Crossvalidation was carried out for $\mathrm{P}, \mathrm{K}, \mathrm{Ca}, \mathrm{Fe}, \mathrm{Mn}$, and $\mathrm{Si}$ with linear correlation coefficients ranging from $0.8704(\mathrm{P})$ to $0.9778(\mathrm{Ca})$. As chemicals were avoided in sample preparation, there was no generation of toxic residues.

Electrothermal sample vaporization and laser ablation are powerful tools for elementar determination by plasma techniques usually without sample pretreatment. Applications include direct analysis of biological materials for the determination of chlorine (De Gois et al. 2015) and bioimaging of $\mathrm{Cd}$ and micronutrients in seeds of sunflower (Pessoa et al. 2017). In spite of the analytical potential, these approaches demand high energy and costs. Alternatively, online coupling of MIC to flame furnace atomic absorption spectrometry was proposed as an ingenious approach for trace analysis of $\mathrm{Cd}$ and $\mathrm{Pb}$ in botanical samples (Barin et al. 2008). Pellets of samples were weighed on a filter paper, wrapped, and placed into the glass chamber. The transient signals were recorded after MW-induced ignition. External calibration can be performed with reference solutions placed directly on the filter paper.

\section{ELECTROANALYSIS}

Electroanalysis fulfills several of the requirements of $\mathrm{GAC}$, being attractive for real time measurements without analyte derivatization (Koudelka-Hep and Van der Wal 2000). The advantages are potentialized with microelectrodes, in which the ohmic drop (IR) is virtually negligible, enabling electrochemical studies of redox systems in absence of support electrolyte. As a consequence, consumption of conditioning solutions (e.g. buffers or electrolytes) is avoided or minimized. Other green characteristic of microelectrodes refers to their exploration in microscopic domains, thus requiring very low sample volumes. Moreover, these sensors have been exploited for in situ analysis as exemplified by environmental monitoring of 
oxygen (Prien et al. 2005) and copper (Wang et al. 1995).

Other advantage of the electrochemical methods aligned to the GAC is related with the fabrication of electrochemical microfluidic analytical devices, termed as ePADs (Mettakoonpitak et al. 2016) by using paper as substrate. These devices are inexpensive, lightweight, flexible, easy to use, and disposable by burning, which avoid waste generation after biological or environmental analysis. Because of these characteristics, ePADs are attractive for point-of-care applications. Additionally, due to the large availability and their chemical and physical properties, papers have been widely applied in analytical chemistry (Martinez et al. 2007, Yang et al. 2017). In this sense, De Araújo and Paixão (2014) proposed the use of Ag tracks painted in office paper to fabricate cheap and reliable electrochemical sensors to quantify $\mathrm{Cl}^{-}$ and $\mathrm{Pb}^{2+}$ in environmental samples and a lowcost three-dimensional ePAD using pencil handwriting was proposed for determination of traces of p-nitrophenol in waters (Santhiago et al. 2014). A greener process for fabrication of ePADs was recently proposed (De Araújo et al. 2017) relying on the use of a laser scribed approach with a $\mathrm{CO}_{2}$ laser machine, instead of chemicals (e.g. inks and organics solvents).

Electrochemistry can also be used for chemical derivatization without toxic reagents. In this sense, it is feasible to convert chemical species difficultto-oxidize (or reduce) in more easily oxidizable (or reducible) species. In situ electrochemical sample pretreatment or generation of electroactive species are also feasible. An array of electrodes can be used to perform the electrochemical conversion and sensing of the species generated. For example, this strategy was exploited for electrochemical sample pretreatment aiming to avoid chemical interferences with negligible waste generation (Silva et al. 2016b). Electrolysis has been also exploited to separate the analyte from matrix species that could interfere in the analytical determination by atomic spectrometry (Beinrohr 1995), also avoiding addition of toxic chemicals and waste generation. Additionally, in the context of GAC, electrochemical derivatization ought to avoid the formation of chemical species more hazardous that the original ones. This drawback was observed when latrine wastewater with high concentrations of chloride and organic matter was submitted to electrochemical pretreatment, generating toxic byproducts, such as chlorate, perchlorate, and chlorinated organic compounds (Radjenovic and Sedlak 2015).

Aiming at GAC, Hg-based electrodes have been replaced by alternative materials in highly sensitive stripping voltammetric methods for different applications. In this context, bismuth films are a greener alternative because of the lower toxicity and minimum threat to the environment because of the quite low solubility of its compounds in water. Brazilian contributions related to bismuth film electrodes for stripping analysis are significant, with ca. $6 \%$ of the articles available in the literature according to a survey at the ISI Web of Science database. Bismuth thin films have been deposited on different substrates such as copper from circuit boards (De Figueiredo-Filho et al. 2017) and pyrolyzed paper (Silva et al. 2017). The former approach was applied for determination of diquat and paraquat pesticides in waters with LODs lower than $10^{-7} \mathrm{~mol} \mathrm{~L}^{-1}$, whereas a pyrolyzed paper was the substrate for disposable working electrodes aiming at determination of trace metals with LODs of $0.26,0.25$, and $0.39 \mu \mathrm{g} \mathrm{L}^{-1}$ for $\mathrm{Zn}^{2+}, \mathrm{Cd}^{2+}$, and $\mathrm{Pb}^{2+}$, respectively (Silva et al. 2017). Electrochemical sensors modified with bismuth have been also exploited for determination of herbicides (Gerent et al. 2015), fertilizers (Jost et al. 2016), pesticides (Lezi and Economou 2015), ecotoxic nitrophenols (Lezi et al. 2014), heavy metals (Bansod et al. 
2017) and hormones (De Lima and Spinelli 2013) in environmental samples.

Boron doped diamond (BDD) electrodes are also interesting greener alternatives to mercury electrodes because of the large potential windows and low background current. The pioneer work relying on pretreatment of the surface of the BDD electrode in very negative potential (Suffredini et al. 2004) opened new possibilities in this field, with applications to pesticide monitoring that could not be oxidized by conventional electrodes (Codognoto et al. 2004, Pedrosa et al. 2008, Selva and Paixão 2016a, Costa et al. 2017).

Copper layers freshly deposited in some electrodic materials electrocatalyze the nitrate reduction in potentials lower than in bare electrodes (Desai et al. 2009), but the electrodeposition prior to each analysis often causes sample contamination with the metal. Alternatively, the in situ generation of low amounts of copper ions followed by the immediate cathodic reduction based on stripping techniques was proposed (Paixão et al. 2007). Further, this approach was exploited with recycled flat copper cables as electrochemical nitrate sensors (Silva et al. 2013). The reuse of electronic wastes to fabricate electrochemical sensors is a sustainable approach as demonstrated by reusing gold CD-R (Angnes et al. 2000) and circuit chips (Augelli et al. 1997) for sensing of copper and mercury in different kinds of samples, respectively. High detectability (5 $\mu \mathrm{g} \mathrm{L}^{-1} \mathrm{Cu}$ and $10 \mu \mathrm{g} \mathrm{L}^{-1} \mathrm{Hg}$ ), and good reproducibility between different devices were achieved. Other approach to increase the reproducibility and scalability involved a toner mask (Lowinsohn et al. 2006). However, the electrodes produced from the microchips did not show the same reproducibility due to the homemade fabrication.

Electrochemical detection in microflow systems is a powerful analytical tool for GAC due to portability and low energy demand (thus suitability for point-of-care measurements) as well as the minimization of reagent consumption and waste generation. As an example, this approach was explored for detection of the hormone estriol in waters by consuming only $2 \mu \mathrm{L}$ of sample (Ochiai et al. 2017). A cotton thread was used as microfluidic channel, where the solutions flew by capillarity, and screen-printed electrodes modified with carbon nanotubes were exploited for amperometric detection. Other greener alternative was the recirculation of the carrier solution in the electrochemical cell (Franco et al. 2016). Thus, low reagent consumption and waste generation were achieved even by using high flow rates $(7 \mathrm{~mL}$ $\min ^{-1}$ ), which was enough to achieve a sampling rate of $240 \mathrm{~h}^{-1}$.

Batch injection analysis (BIA) involves injection of a low sample volume (10-30 $\mu \mathrm{L})$ directly on the surface of an electrode placed into a large volume of an electrolyte, usually by using an automatic micropipette (Wang and Taha 1991). In this way, mass transport of the analyte is improved and a transient signal is obtained because of the joint effect of convection and diffusion. The same electrolyte can be used for several measurements because its volume is quite high in relation to the analyte amount; the process is then inherently more environmental friendly. Determination of paraquat (Simões et al. 2007), carbendazim, hydroquinone, and catechol (Caramit et al. 2015), as well as the picoxystrobin fungicide (Dornellas et al. 2015) in waters illustrate some environmental applications by using glassy carbon, screen-printed carbon, and BDD electrodes, respectively. In other green approach, electrochemical transducers were modified with natural enzymes obtained from vegetables, such as peroxidases (Vieira et al. 2003). The use of the natural tissues increase enzyme stability because the species is kept in its natural environment and the chemicals needed for enzyme purification are avoided.

Electrochemical techniques are also compatible with ionic liquids, which are greener and safer 
than the traditional solvents, including low vapor pressures. Additionally no additional electrolyte is required for the electrochemical measurements (Tsuda and Hussey 2007). Ionic liquids have been widely used in analytical chemistry (Shangguan et al. 2010), but application to determination of species of environmental relevance was not reported, which is an opened field in this area.

\section{SEPARATION TECHNIQUES}

Generation of high amounts of toxic wastes is often attributed to separation techniques either in sample processing or in the clean-up step. However, some approaches have been proposed to minimize or eliminate the hazardous solvents and products associated with the analytical process. This applies to gas chromatography (GC) that uses non-toxic gases instead of solvents for separation and it is often considered a technique with low environmental impact. Of course, when chemical derivatization is required (e.g. to yield volatile species), waste generation needs to be taken into account. On the other hand, conventional LC requiring long run times on large internal diameter columns consumes considerable amounts of solvents and generates substantial waste amounts. Common HPLC run involves a mobile-phase flow rate of about $1.0 \mathrm{~mL} \mathrm{~min}^{-1}$, which daily generates a high volume of organic solvent effluents that need to be suitably disposed.

More environmentally friendly LC can be achieved by the reduction of system dimensions, and consequently reduction of both solvent consumption and waste generation, as well as by the use of less hazardous eluents. The challenge is to reduce waste volumes and toxicity without hindering chromatographic resolution.

\section{Miniaturization}

Miniaturized LC and reduction of column internal diameter in conventional HPLC have gained updated interest in recent years, moved by greener separations and lower costs with both mobile and stationary phases (Gama et al. 2013). Reduction of the flow rate allows using more expensive mobile phases in specific applications, such as additives or deuterated solvents, without a significant impact on the analysis cost (Nazario et al. 2015). Different mobile or stationary phases enable new interaction mechanisms and improve the chromatographic selectivity.

Large amounts of solvent are saved when comparing miniaturized and conventional LC techniques. techniques. For example, a mixture of 8 alkylbenzenes can be separated on a 300$\mu \mathrm{m}$ i.d. column using only $39 \mu \mathrm{L}$ of acetonitrile in comparison to $12 \mathrm{~mL}$ by using conventional HPLC (Welch et al. 2010). The 99.5\% reduction in solvent consumption and waste generation was accompanied by decrease on the run time and the chromatographic separation profile was not affected. An additional advantage of miniaturization is the lower sample consumption, which is relevant for e.g. clinical, biomedical, and forensic applications (Needham 2017). Because of the reduction in the column dimensions, injection volumes in miniaturized systems are significantly decreased from several $\mu \mathrm{L}$ to a few $\mathrm{nL}$, also reducing solvent spent and waste generation in both sample preparation and analytical determination.

Another greener aspect of miniaturized LC is that only a small quantity of the stationary phase is needed for packing a small i.d. column. This can lead to significant cost savings for analyses using expensive stationary phases, such as those based on bioaffinity interactions. The lower consumption of reagents and solvents on the synthesis of the stationary phases are also in agreement with GAC principles.

New stationary phases for miniaturized LC involve e.g. synthesis of polymer monolithic materials (Gama et al. 2017), and new silicabased packings (Weller et al. 2017), generally 
for separation of small molecules. The novel phases have shown performance similar to the commercially available ones, with improved selectivity for some compounds (Majors 2000). In spite of the advantages related to the miniaturized LC, the high cost of acquisition and maintenance of these instruments have limited the number of applications.

Application of shorter columns, keeping the i.d. of the traditional ones, is an interesting approach of miniaturization because no adjustments on HPLC instrument are required. The GAC aspect of this option is the simple reduction of the solvent consumption in shorter separation runs. Frequently, some loss of chromatographic resolution is observed for these short columns, but this is not critical for several applications.

Submicrometric particles are particularly attractive for green chromatography. Although backpressure increases significantly, thus requiring special pumps for ultra-high pressure LC systems, separation times and solvent consumption using small particles are reduced up to one order of magnitude when compared to columns packed with larger particles (Kaljurand and Koel 2011).

Microscale separations can also be performed in microchip devices. Chromatographic separation can be carried out in devices of a few centimeters, but microchips have been most usual in electrophoresis (Breadmore 2012), because neither valves nor pumps are needed to perform the separation. By requiring minimal sample, solvent, and sorbent amounts, microchip separation is an interesting GAC approach.

Nowadays, applications of microchip separations are mainly focused on bioanalysis, for both small analytes and macromolecules, including the classical use for ion analysis (Freitas et al. 2016). Whole cells, tissue extracts, metabolites, and biomarkers are frequently analyzed in microchips and require specific interactions for complete separation (Štěpánová and Kašička
2017). In these cases, high selectivity is achieved by immobilization of bioaffinity-based structures on micro/nanochannels, aiming at specific interactions with the analytes.

One of the most recent advance in microchip technology was the development of inexpensive paper-based devices (Chagas et al. 2016). Some devices can join both sample preparation and separation in a single platform, even for complex matrices (Niu et al. 2018). Differently from traditional materials, e.g. glass and organic polymers, that requires special methodologies for microchip design, paper microfluidic devices are generally fabricated by environmentally friendly and affordable technologies.

\section{Greener alternative solvents}

In addition to the solvent reduction through miniaturization, replacing toxic solvents also significantly contributes to GAC. Usually, normal phase chromatography, and water-based reversedphase HPLC are performed with two or one non-green solvent, respectively. Although highly desirable, replacement of solvents should not hinder the chromatographic efficiency (e.g. loss of resolution and selectivity). Sometimes, this drawback can be overcome by some experimental adjustments.

Greener alternatives for mobile phase constituents, such as water, ethanol, or carbon dioxide, can reduce the generation of toxic wastes. In the most appropriate situation, all solvents used are green, as well as the waste generated in the experiment, as observed for ethanol-based HPLC and heated water HPLC (Welch et al. 2010). Table II summarizes the solvents commonly employed in LC separations and their classification for use as green eluent. Notably, there are alternatives for the replacement of solvents classified as undesirable.

LC separations have been predominantly carried out in reversed-phase mode, using a 
hydrophobic stationary phase and a mobile phase generally composed by a mixture of a polar organic solvent and water. The wide use of acetonitrile is based on its remarkable physical properties, such as low viscosity, miscibility with water, and UV-transparency at low wavelengths (Ribeiro et al. 2004). However, from the GAC point of view, acetonitrile is not suitable because of high flammability, volatility, and toxicity. Consequently, a LC waste containing acetonitrile has high cost of disposal. In this context, replacement of acetonitrile is probably the main goal in green LC.

Methanol should be selected instead of acetonitrile whenever possible, because of the lower toxicity. Moreover, one important aspect is the disposal of mobile phase components that requires special waste treatments. High disposal costs are especially valid for acetonitrile, which requires detoxification of $\mathrm{HCN}, \mathrm{NO}_{2}$ formation, among other steps, when compared to methanol (Vanhoenacker et al. 2010).

Ethanol is an alternative as a less toxic and biodegradable solvent for LC separations and may replace acetonitrile in several applications. In this sense, ethanol was explored in reversed-phase LC as an acetonitrile substitute in the determination of natural product fingerprints (Funari et al. 2014). Recently, ethanol-water mobile phases were proposed for routine analysis in the pharmaceutical industry (Totoli and Salgado 2015).

Because chromatographic performance using ethanol is inferior to acetonitrile as a reversedphase mobile phase, the temperature control during separation is important to minimize peak broadening and loss of the chromatographic resolution. Generally, separation using ethanol is performed under relatively higher temperatures (e.g. $45^{\circ} \mathrm{C}$ ), to reduce the viscosity of the ethanolwater mixture and to enhance the chromatographic performance. The higher temperature requires adjustments in chromatographic instrumentation and also modern column packings, as fused-
TABLE II

Solvent selection guide for green eluents for $\mathbf{L C}$ separations. Adapted from Alfonsi et al. 2008.

\begin{tabular}{lcc}
\hline Preferred & Usable & Undesirable \\
\hline Water & Acetonitrile & Pentane \\
Acetone & Toluene & Hexane \\
Ethanol & Cyclohexane & Dichloromethane \\
Isopropanol & Acetic acid & Dimethylformamide \\
Ethyl acetate & Ethylene glycol & Chloroform \\
Methanol & Tetrahydrofuran & Pyridine \\
Isopropyl & Dimethyl & Dioxane \\
acetate & sulfoxide & \\
Methyl ethyl & Xylenes & Carbofuran \\
ketone & & \\
Butanol & & Benzene \\
& & Carbon tetrachloride \\
\hline
\end{tabular}

core $2.7 \mu \mathrm{m}$-particles packed columns, that are more resistant to heating. These hindrances have restricted the replacement of acetonitrile by ethanol in routine chromatography.

Another alternative to replace acetonitrile as LC mobile phase is heat water, especially superheated water $\left(>100^{\circ} \mathrm{C}\right)$. Superheated water is an interesting green alternative for reversedphase LC separations, replacing (totally) organic constituents from mobile phase. The high temperature decrease the solvent polarity and thus increase the elution strength of the aqueous mobile phase (Borges et al. 2010). Furusawa and Tsumatani (2012) determined melamine in milk, using only water (at $25^{\circ} \mathrm{C}$ ) as mobile phase. The separation was performed in reversed-phase mode, employing octadecyl-bonded silica as stationary phase. The green chromatographic method yielded recoveries higher than $96.8 \%$, with a coefficient of variation $(\mathrm{CV})$ lower than $2.0 \%$, thus being attractive for routine analysis.

Sequential injection chromatography (SIC), a type of lower pressure chromatography, was exploited by Chocholouš et al. (2017) for separation of red colorants in beverages. The fast chromatographic method was based on a cyano 
monolithic column and aqueous ammonium phosphate solutions as mobile phase (gradient mode).

Supercritical fluids can also replace toxic solvents in LC separations. These fluids show properties intermediate between a liquid and a gas, making them unique mobile phases. Carbon dioxide is the main mobile phase in supercritical chromatography (SFC) because the critical point is achieved under mild pressures and temperatures, combined to the non-toxicity and its enhanced chiral recognition (Sandra et al. 2010). The addition of an organic modifier to supercritical $\mathrm{CO}_{2}$ expanded the use to both reversed- and normal-phase separation modes (Lesellier and West 2015). SFC was explored for capillary separations (Tavares et al. 2001) and sample preparation, especially for isolation of natural products (Celeghini et al. 2001, Vasconcelos et al. 2000, Vilegas et al. 1993). A recent application refers to determination of organic pollutants from environmental samples (Yeung et al. 2017) and analysis of food and soil contaminants (Tao et al. 2018). The most important drawback on SFC is the high cost of equipment and maintenance, which limits the wide use of this greener separation technique.

\section{FLOW ANALYSIS}

Flow analysis is a versatile alternative for the development of greener procedures as discussed in a critical review article (Melchert et al. 2012). This process inherently allows the reduction of reagent consumption with a consequently lower waste generation, as well as minimizes the risks to the analyst by sample processing in a closed system. Moreover, greener procedures are achieved by exploiting the highly reproducible timing and sample processing conditions.

Development of flow analysis and GAC are closed related as previously demonstrated (Melchert et al. 2012). Several flow modalities have been proposed to minimize reagent consumption and waste generation without hindering the analytical performance and some approaches are shown in Fig. 2. This is usually achieved by adding the reagent only in the sample zone instead of the continuous introduction, characteristic of single line and confluent streams flow injection analysis. This is achieved in the merging zones (Bergamin-Filho 1978, Fig. 2a) and intermittent flow (Zagatto et al. 1980, Fig. 2b) approaches by inserting the reagent simultaneously to the sample aliquot, whereas recirculation of solutions occurs at the alternative resting position of the injector. This characteristic is also typically observed in monosegmented flow analysis (Pasquini and Oliveira 1985, Fig. 2c) but reagent saving can be higher because of the limited sample dispersion provided by segmentation by air bubbles. Intermittent addition of reagents is also inherent to multicommutation (Reis et al. 1994) and multi-pumping (Lapa et al. 2002) approaches, as well as flow-batch analysis (Diniz et al. 2012), but with higher versatility provided by independent solution management with discrete commuters. These approaches are schematically illustrated in Fig. 2d. Other alternative are the micro-flow analyzers, such as those build up with polymeric materials (Fonseca et al. 2007, Fig. 2e) and the micro-flow batch analyzers (Monte-Filho et al. 2011). Sequential injection analysis - SIA (Ruzicka and Marshall 1990, Fig. 2f) also stands out by increased versatility and low reagent consumption, as the sample and reagent aliquots can be aspirated only when needed, based on a multiport valve. Then, different chemistries can be exploited without changing the manifold hardware. A further reduction in reagent consumption is provided by the lab-on-valve (LOV) approach (Wang and Hansen 2003, Fig. 2g), which integrates detection at the head of the multiport valve, thus consuming reagents in the scale of micro and submicroliters.

Development of flow-based reagentless procedures can be exemplified by the determination 


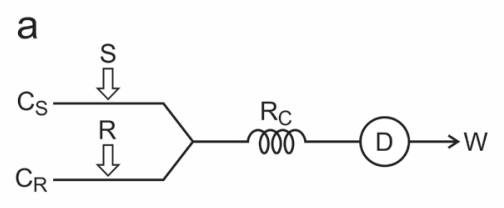

b
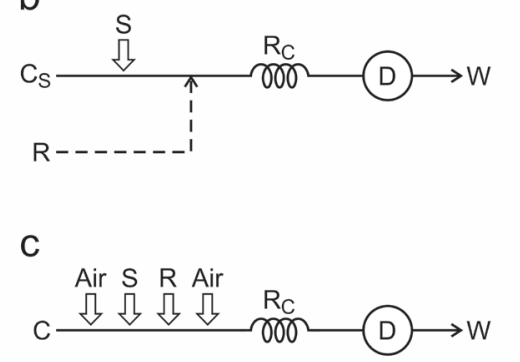

d

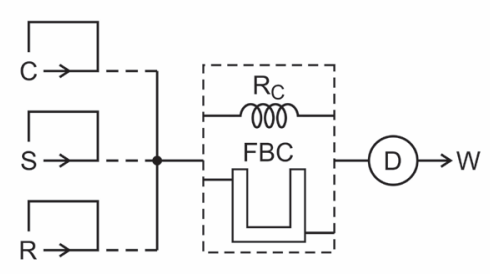

e

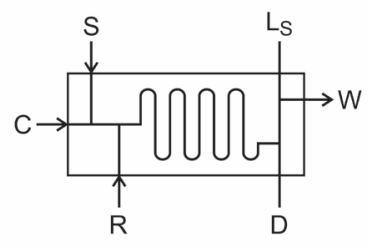

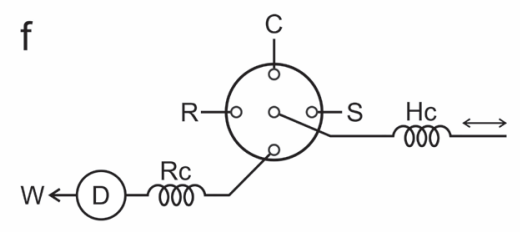

g

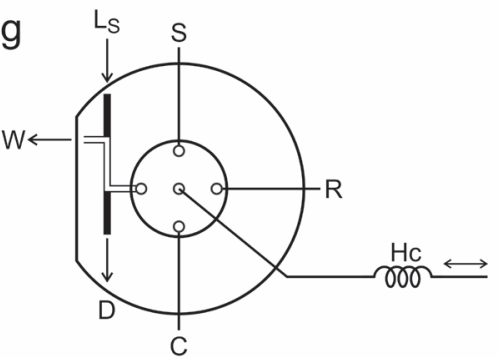

Figure 2 - Schematic representation of some environmental friendly flow modalities presented by Brazilian authors: (a) merging zones; (b) intermittent flows; (c) monosegmented flow analysis; (d) multicommutation and multi-pumping (with dispersion in Rc) and flow-batch analysis (mixing in FBC); (e) micro-flow analyzers; (f) sequential injection analysis and (g) lab-on-valve. C, Cicarriers; S-sample; R-reagent solution; Rc-coiled reactor; Hc-holding coil; FBC-flow-batch chamber; D-detector; LS-light source; W-waste vessel.

of ethanol in beverages by exploiting the effect of the analyte on the surface tension of aqueous solutions (Borges et al. 2006) or the Schlieren effect (Costa et al. 2004). In the former, sample drops were reproductively generated between an infrared LED and a phototransistor. Attenuation of the radiation beam according to the size of the droplet, which depends on the ethanol concentration, was the measurement basis. A linear regression was achieved within 0.17 and $5.14 \mathrm{~mol} \mathrm{~L}^{-1}$ of ethanol and $\mathrm{CV}$ was estimated at $2.5 \%$. The other alternative involved the refractive index gradients reproductively formed when an aliquot of alcoholic beverage was processed in a single line manifold under limited mixing conditions (Costa et al. 2004). Data treatment by Soft Independent Modelling of Class Analogy (SIMCA) allowed detection of adulterations in brandies, cachaças, rums, whiskies, and vodkas. Unlike the chromatographic procedures generally used for the determination of ethanol, the proposed procedures did not use any chemical reagent and a low amount of a non-toxic residue is generated.
Other ingenious strategy was exploited for reagentless determination of free glycerol in biodiesel involving sonoluminescent detection in a flow-batch system (Diniz et al. 2013). Water was used for analyte extraction instead of the usual mixture of organic solvents (e.g. ethanol and hexane) with water. The sonoluminescence yielded by excited hydroxyl radicals was quenched by glycerol, because the thermal energy yielded by cavitation (induced by a piezoelectric device) was partially consumed for the rupture of chemical bonds of the analyte. The LOD and the sampling rate were estimated at $4.0 \mathrm{ng} \mathrm{kg}^{-1}$ and 14 determinations per hour, respectively. Reagents used for spectrophotometric or fluorimetric determination of glycerol such as acetylacetone, acetic and hydrochloric acids, and ammonium acetate were then avoided.

Replacement of toxic reagents without hindering the analytical performance is another alternative aiming at GAC and the characteristics of flow systems are attractive for this task. In this sense, hydrophilic solvents composed by medium- 
chain saturated fatty acids were proposed for inline extraction of ofloxacin in human urine samples (Vakh et al. 2016). Initially, a homogeneous phase is formed from a diluted urine sample, hexanoic acid and sodium carbonate solution into a mixing chamber. The injection of sulfuric acid promoted the formation of hydrophobic microdroplets of the fatty acid assisted by the effervescence provided by $\mathrm{CO}_{2}$ evolution, which provided microextraction of ofloxacin and phase separation. The extraction process required only $50 \mu \mathrm{L}$ of hexanoic acid and 2 min for analyte extraction.

The selective determination of nitrate in natural waters was based on direct UV measurements, after analyte separation from interfering species using an anion-exchange column in a flow injection system (Melchert and Rocha 2005). Thus, the use of toxic (cadmium filings) and carcinogenic (N-(1Naphthyl)ethylenediamine) reagents were avoided and the only reagent was dilute perchloric acid, equivalent to $18 \mu \mathrm{L}$ of the concentrated acid (or $300 \mu \mathrm{mol})$ per determination. The strategy was effective for separation of nitrate from organic and inorganic interfering species, including humic acid, thus avoiding errors between 14 and $60 \%$ when samples were analyzed without separation. The same mini-column containing $180 \mathrm{mg}$ of the anion-exchanger could be used in up to 500 measurements, also avoiding waste generation.

The use of natural materials as biosorbents is also a trend for separation, preconcentration, and even chemical speciation. These materials can also be classified as greener because the consumption of reagents and solvents in the preparation of the synthetic adsorbents is avoided. Advantages of flow-based biosorption include higher sample throughputs, feasibility of kinetic discrimination, and applicability of the sorbent in several retention/ elution cycles. The latter characteristic also minimizes waste generation. In this context, peat was used as adsorbent for copper separation and preconcentration in a multicommuted flow system directly coupled to FAAS (Gonzáles et al. 2009). The mini-column was used for up to 100 sampling cycles, with a $\mathrm{CV}$ estimated at $3.3 \%$ and an enrichment factor of 16. As copper was adsorbed in its ionic form, complexation was not required, thus eliminating the use of (often toxic) chelating agents such as ammonium diethyldithiophosphate or ammonium pyrrolidine dithiocarbamate.

Another greener alternative refers to the use of natural materials as enzymatic sources, as demonstrated by the use of jack bean as source of urease in the determination of urea in human serum (De Faria et al. 1991). A greener strategy involving conductometric measurements was also exploited for detection of the ammonium ions produced in the enzymatic reaction. The use of a crude extract of sweet potato root as a source for polyphenol oxidase was further investigated aiming at flowinjection spectrophotometric determination of e.g. sulfite (Fatibello-Filho and Vieira 1997) and total phenols (Vieira and Fatibello-Filho 1998). The carrier solution of the crude extract in phosphate buffer was the only reagent needed and sample pretreatments were not required. Storage at low temperature $\left(4^{\circ} \mathrm{C}\right)$ to maintain enzyme activity, variability of the activity for different vegetables, and the need for elimination of ascorbic acid interference are critical aspects of these procedures.

Organic solvents are replaced by surfactants in cloud point extractions, which can also be carried out in flow systems (Melchert and Rocha 2016). Most of the approaches involve dilution of the surfactantrich phase (e.g. to decrease viscosity), which requires organic solvents and causes undesirable analyte dilution. An alternative approach exploited a flow system with solenoid micropumps for retention of the surfactant-rich phase directly at the optical path of the spectrophotometric cell (Frizzarin and Rocha 2014). An on-line neutralization reaction induced the cloud point, thus avoiding the need for an external heating device. The potential was demonstrated by determination 
of iron as a 1-(2-pyridylazo)-2-naphthol complex. The sampling rate and CV were estimated at 26 determinations per hour and $2.3 \%$, respectively. The low consumptive index $\left(0.022 \mathrm{~mL}^{-1}\right)$ indicated that the sample $(200 \mu \mathrm{L})$ was efficiently used, yielding an enrichment factor of 8.9. Another advantage was the elution of the surfactant-rich phase by the aqueous carrier, avoiding the use of organic solvents. The main limitation refers to the use of higher sample volumes aiming at improvement in sensitivity because the amount of the surfactantrich phase to be retained at the flow cell is limited.

As previously discussed, liquid-liquid microextractions are an alternative to minimize the consumption of organic solvents. This characteristic is emphasized in flow-based microextractions and different approaches have been successfully adopted (Alexovic et al. 2016, Kocurova et al. 2013, and Miró and Hansen 2013). For example, a liquid-liquid microextraction with only $40 \mu \mathrm{L}$ of chloroform was performed for the determination of anionic surfactants in natural waters by the methylene blue method (Pereira and Rocha 2013). Formation and extraction of the ion-pair was carried out in a multicommuted flow system with spectrophotometric detection in a glass tube without phase isolation. To this aim, the aqueous phase formed by sample and the dye was sandwiched between two $\mathrm{CHCl}_{3}$ aliquots aiming at extraction at the interfaces and through the film of the solvent formed at the wall of the hydrophobic tube. The approach decreased by 2200 -fold the amount of $\mathrm{CHCl}_{3}$ in comparison to the batch official procedure with a $\mathrm{CV}$ as low as $1.5 \%$.

Advantages provided by miniaturization, automation, and integration of sample pretreatment have been achieved in SIA. As an example, SIA was exploited for determination of melamine in milk samples, exploring the effect of the analyte on the formation of a fluorescent species in the reaction of hydrogen peroxide with sesamol catalyzed by peroxidase (Faustino et al. 2017). An extraction unit composed by two polytetrafluorethylene blocks separated by a microporous hydrophobic membrane was coupled to a rotary valve and an ionic liquid solution was used as acceptor. About $200 \mathrm{~s}$ was spent for the extraction, thus limiting the sampling rate, but recoveries from 93 and 105\% were achieved.

Also focusing on a milk adulterant, melamine determination was carried out in SIC by replacing the organic solvents by a surfactant (sodium dodecyl sulphate, SDS) in the chromatographic separation (Batista et al. 2014). The micellar-medium was suitable for separation of melamine, which is not efficient in reversed-phase chromatography and the procedure also included on-line sample preparation by simple dilution of the sample with the SDS solution aiming to extract fat to the micelles of the surfactant. A linear response was observed from 2.0 to $6.0 \mathrm{mg} \mathrm{L}^{-1}$ of melamine with a $\mathrm{CV}$ of $2.9 \%$. In other SIC application, a green analyte extraction (water instead of organic solvents) and a significant reduction of solvent consumption in chromatographic separation (up to 100-fold lower consumption of acetonitrile) were combined for determination of the phytohormone salicylic acid in plant materials (Barrientos et al. 2016).

A greener preconcentration and determination of carbamate pesticide residues was also the focus of a flow-based procedure by exploiting an hollow fiber filled with dodecanol for analyte extraction (Fu et al. 2009). Enrichment factor of carbaryl was estimated at 300 , but analytical routine took 22 $\min$. The hollow fiber could be operated for $150 \mathrm{~h}$ and $50 \mu \mathrm{L}$ of dodecanol was used for regeneration.

Reduction of reagent consumption and the consequent decrease in waste generation can be also achieved by solid phase spectrophotometry (optosensing), especially when reversible analyte retention (i.e. elution of the analyte without removing the immobilized reagent) is viable. In this sense, an environmental friendly procedure involved iron(II) retention on 1-(2-thiazolylazo)-2- 
naphthol (TAN) immobilized on C18-bonded silica as a brown complex (Teixeira and Rocha 2007). After the spectrophotometric measurement, the elution was carried out with dilute hydrochloric acid without removal of the complexing agent and the solid-support was used for at least 100 measurement cycles. The sampling rate and $\mathrm{CV}$ were estimated at 25 measurements per hour and $4.0 \%$, respectively. In comparison with the conventional spectrophotometric procedure, there was a reduction of 1000-fold in the consumption of TAN.

Several approaches have been proposed for miniaturization of flow injection analyzers, which present the intrinsic advantage of reducing drastically the consumption of samples and reagents (Trojanowicz and Kolacinska 2016). For example, urethane acrylate microfluidic devices were designed for determination of hypochlorite and nitrite ions based on the luminol chemiluminescence (Sampaio and Fonseca 2015). These inexpensive devices can be built quickly by the photolithographic process, supporting flow rates of up to $2.0 \mathrm{~mL} \mathrm{~min}^{-1}$ without leakage. Repeatability and sampling rate were estimated at $0.4-0.6 \%$ and 90-60 $\mathrm{h}^{-1}$ for hypochlorite and nitrite, respectively, with a consumption of $7.9 \mu \mathrm{L}$ of sample and 1.60 $\mu \mathrm{g}$ luminol per determination, generating $24 \mathrm{~mL}$ of waste per hour.

\section{CHEMOMETRICS}

One of the goals of GAC is to reduce the number of experiments involved in chemical analysis, thus also reducing the waste amount and time spent in the analytical process. In this sense, chemometrics may help in the selection of variables, experimental design, classification, and quantification of analytes, including screening methods with minimized consumption (or even without using) of chemicals. The number of samples to be analyzed by more time-consuming and less environmental friendly procedures is then minimized.

Because of the instrumental evolution and novel analytical strategies, chemical analysis is tending to direct measurements of solid, liquid, and gaseous samples. This is intrinsically a greener approach and mathematical models and algorithms to extract reliable quantitative or qualitative information from these chemical systems take a decisive role in this context. This strategy can be exemplified by applications of chemical sensors, as those based on electronic tongues and noses. These analytical instruments comprises an array of stable, sensitive, and low-selective sensors coupled to a suitable approach of pattern recognition and/or multivariate calibration for data processing (Vlasov et al. 2005). Vibrational spectrometric techniques such as near and mir infrared and Raman, as well as fluorescence, UV-vis spectrophotometry, and LIBS allow obtaining a direct chemical fingerprint of samples without (or with minimal) sample preparation.

One interesting approach refers to an electronic tongue based on an array of four electrochemical sensors modified with a polymeric layer, which was developed to classify soil samples in function of nutrient levels. Based on Interactive Document Map (IDMAP), Sammon's Mapping (SAMMON), and PCA, suitable discrimination of soil samples was achieved by using raw data, i.e. without any sample pretreatment.

Also exploiting chemometric tools, elemental concentrations (Al, B, Ca, Mg, Zn, Cu, Mn, Fe, Na, and $\mathrm{Si}$ ) obtained by LIBS allowed comparison of four wood species (Cedrela fissilis, Ocotea porosa, Hymenolobium petraeum, and Aspidosperma subincanum). The emission signals were used as input of a PCA and because of the fast in situ analysis, the obtained results could be a powerful tool to protect endangered wood species. Also using PCA, direct voltammetric measurements were exploited to classify carbamate pesticides (aldicarb, 
carbaryl, carbofuran, methomyl, and propoxur) in water for environmental control purposes (Selva and Paixão 2016b).

The use of smartphones to extract analytical information is an interesting trend in Analytical Chemistry (Roda et al. 2016) because each citizen could have your pocket (analytical) instrument. Free application softwares devoted to image capture and data treatment are available (Helfer et al. 2016) making feasible the wide application. Digital images acquired directly from the sample or after a selective colorimetric chemical reaction have been used for analytical purposes (Yang et al. 2016, Zhang and Liu 2016). Thus, simple, rapid, inexpensive, and sometimes non-destructive procedures can be attained, often coupled to chemometrics analysis. In this sense, a paper-based spot-test was proposed to discriminate explosives (triacetone triperoxide, hexamethylene triperoxide diamine, 4-amino-2-nitrophenol, nitrobenzene, and picric acid) by using less than $5 \mu \mathrm{L}$ of reagents. $R, G$, and $B$ values extracted using a smartphone after the colorimetric reaction were submitted to PCA analysis. A similar approach was used to discriminate quality of meat samples using 5 spots fabricated in cellulose acetate for detection of bacteria (Bueno et al. 2015a) and amines (Bueno et al. 2015b). PCA with digital images acquired from $5.0 \mathrm{~mL}$ of biodiesel samples in a Petri plate were exploited to classify the samples in relation to the feedstocks (cottonseed, sunflower, corn, or soybean) (Costa et al. 2015). One of the limitations about image detection is the necessity to control the ambient light using a chamber or using mathematical approach (Jia et al. 2015), as well as, the focus distance and other parameters to avoid errors in the analysis (Morbioli et al. 2017).

The works previously discussed aimed at discrimination or classification of samples. Additionally, different strategies for multivariate calibration in accordance with GAC have been proposed. For instance, X-ray fluorescence (Da-
Col et al. 2015) was used to quantify directly $\mathrm{Na}$ and $\mathrm{K}$ in table, marine and low-sodium salts using the entire spectra instead of peak values as in the univariate approach.

Spectroscopy and chemometrics have been exploited for a diversity of applications, including the evaluation of distribution of lignin and cellulose at wood surfaces (Colares et al. 2015), detection of adulteration in gasoline samples (Paulo et al. 2012), estimation of octane number (Mendes et al. 2012) or quality of frozen guava and passion fruit pulps (Alamar et al. 2016), as well as to evaluate waste frying oil blends (Hocevar et al. 2012). In agreement with the principles of GAC, the direct analysis avoids consumption of chemicals for sample preparation resulting in low waste generation.

\section{CONCLUSIONS}

The main Brazilian contributions to GAC were critically revised and clearly demonstrate that this is a well-established research field in Brazil in adherence with the trends toward more sustainable analytical approaches observed worldwide. Highly relevant innovations have been proposed, such as novel flow modalities which consume lower reagent amounts, sample decomposition procedures under mild experimental conditions and consuming lower amounts or even avoiding the use of corrosive acids, novel electrode materials and electrochemical approaches, and alternative reagentless procedures. Several successful approaches towards miniaturization have also been presented, including flow analysis and capillary electrophoresis in microchips, as well as paperbased analytical devices. In this regard, combination of conventional and modern analytical methods and techniques has yielded interesting analytical devices for process control and monitoring of pollutants with minimized wasting of chemicals. Additionally, GAC has also been achieved by 
exploiting chemometrics with relevant applications such as detection of food adulterations and quality control of biofuels. On the other hand, multivariate tools can assist optimization of analytical methods with lower consumption of chemicals.

Whereas Brazil is recognized as a main player in GAC in some subareas, such as sample preparation and flow analysis, contributions in other fields could be improved, such as in green chromatography. Further developments are also needed to make the approaches reliable for routine analysis. With a diversity of analytical problems to be solved in a more environmental friendly way, GAC can be pointed out as a very fertile research area.

\section{ACKNOWLEDGMENTS}

The authors are grateful to the Brazilian agencies' Coordenação de Aperfeiçoamento de Pessoal de Nível Superior (CAPES), Fundação de Amparo à Pesquisa do Estado de São Paulo (FAPESP), and Conselho Nacional de Desenvolvimento Científico e Tecnológico (CNPq) for fellowships and financial support. Prof. E.A.G. Zagatto is thanked for critical comments.

\section{REFERENCES}

ABDEL-REHIM M. 2004. New trend in sample preparation: on-line microextraction in packed syringe for liquid and gas chromatography applications I. Determination of local anaesthetics in human plasma samples using gas chromatography-mass spectrometry. J Chromatogr B 801: 317-321.

ALAMAR PD, CARAMÊS ETS, POPPI RJ AND PALLONE JAL. 2016. Quality evaluation of frozen guava and yellow passion fruit pulps by NIR spectroscopy and chemometrics. Food Res Int 85: 209-214.

ALEXOVIC M, HORSTKOTTE, SOLICH P AND SABO J. 2016. Automation of static and dynamic non-dispersive liquid phase microextraction. Part 1: Approaches based on extractant drop-, plug-, film- and microflow-formation. Anal Chim Acta 906: 22-40.

ALFONSI K ET AL. 2008. Green chemistry tools to influence a medicinal chemistry and research chemistry based organization. Green Chem 10: 31-36.
ALMEIDA JS, ANUNCIAÇÃO TA, BRANDÃO GC, DANTAS AF, LEMOS VA AND TEIXEIRA LSG. 2015. Ultrasound-assisted single-drop microextraction for the determination of cadmium in vegetable oils using high-resolution continuum source electrothermal atomic absorption spectrometry. Spectrochim Acta B 107: 159163.

AMAIS RS, GARCIA EE, MONTEIRO MR AND NÓBREGA JA. 2011. Analysis of biodiesel microemulsions using ICP OES with axial configuration and argon-oxygen plasma. Br J Anal Chem 5: 246-250.

AMORIM FAC, COSTA VC, SILVA EGP, LIMA DD, JESUS RM AND BEZERRA MD. 2017. Multivariate optimization of simple procedure for determination of $\mathrm{Fe}$ and $\mathrm{Mg}$ in cassava starch employing slurry sampling and FAAS. Food Chem 227: 41-47.

ANASTAS PT. 1999. Green chemistry and the role of analytical methodology development. Crit Rev Anal Chem 29: 167-175.

ANDRADE FN, SANTOS-NETO AJ AND LANÇAS FM. 2014. Microextraction by packed sorbent liquid chromatography with time-of-flight mass spectrometry of triazines employing a molecularly imprinted polymer. J Sep Sci 37: 3150-3156.

ANDRADE MA AND LANÇAS FM. 2017. Determination of ochratoxin A in wine by packed in-tube solid phase microextraction followed by high performance liquid chromatography coupled to tandem mass spectrometry. J Chromatogr A 1493: 41-48.

ANGNES L, RICHTER EM, AUGELLI MA AND KUME GH. 2000. Gold electrodes from recordable CDs. Anal Chem 72: 5503-5506.

ARAÚJO GCL, GONZALEZ MH, FERREIRA AG, NOGUEIRA ARA AND NÓBREGA JA. 2002. Effect of acid concentration on closed-vessel microwave-assisted digestion of plant materials. Spectrochim Acta Part B 57: 2121-2132.

ARAÚJO GCL, NOGUEIRA ARA AND NÓBREGA JA. 2000. Single vessel procedure for acid-vapour partial digestion in a focused microwave: $\mathrm{Fe}$ and Co determination in biological samples by ETAAS. Analyst 125: 1861-1864.

ARMENTA S, GARRIGUES S AND DE LA GUARDIA M. 2008. Green analytical chemistry. Trend Anal Chem 27: 497-511.

ARTHUR CL AND PAWLISZYN J. 1990. Solid phase microextraction with thermal desorption using fused silica optical fibers. Anal Chem 62: 2145-2148.

AUGELli MA, NASCIMENTO VB, PEDROTTI JJ, GUTZ IGR AND ANGNES L. 1997. Flow-through cell based on an array of gold microelectrodes obtained from modified integrated circuit chips. Analyst 122: 843-847.

AUGUSTO F, CARASEK E, SILVA RGC, RIVELLINO SRR, BATISTA AD AND MARTENDAL E. 2010. New 
sorbents for extraction and microextraction techniques. J Chromatogr A 1217: 2533-2542.

BALTUSSEN E, SANDRA P, DAVID F AND CRAMERS C. 1999. Stir bar sorptive extraction (SBSE), a novel extraction technique for aqueous samples: theory and principles. J Microc Sep 11: 737-747.

BANSOD B, KUMAR T, THAKUR R, RANA S AND SINGH I. 2017. A review on various electrochemical techniques for heavy metal ions detection with different sensing platforms. Biosens Bioelectron 94: 443-455.

BARIN JS, BARTZ FR, DRESSLER VL, PANIZ JNG AND FLORES EMM. 2008. Microwave-induced combustion coupled to flame furnace atomic absorption spectrometry for determination of cadmium and lead in botanical samples. Anal Chem 80: 9369-9374.

BARRIENTOS MO, BATISTA AD AND ROCHA FRP. 2016. Fast and environmentally friendly determination of salicylic acid in plant materials by sequential injection chromatography. Anal Methods 8: 6398-6403.

BARROS JAVA, SOUZA PF, SCHIAVO D AND NÓBREGA JA. 2016. Microwave-assisted digestion using diluted acid and base solutions for plant analysis by ICP OES. J Anal At Spectrom 31: 337-343.

BATISTA AD, NASCIMENTO CF, MELCHERT WR AND ROCHA FRP. 2014. Expanding the separation capability of sequential injection chromatography: determination of melamine in milk exploiting micellar medium and on-line sample preparation. Microchem J 117: 106-110.

BEINROHR E. 1995. Electrolytic sample pretreatment in atomic spectrometry: a review. Microchim Acta 120: 3952.

BERGAMIN-FILHO H, ZAGATTO EAG, KRUG FJ AND REIS BF. 1978. Merging zones in flow injection analysis. 1. Double proportional injector and reagent consumption. Anal Chim Acta 101: 17-23.

BIZZI CA, FLORES EMM, BARIN JS, GARCIA EE AND NÓBREGA JA. 2011. Understanding the process of microwave-assisted digestion combining diluted nitric acid and oxygen as auxiliary reagent. Microchem J 99: 193-196.

BIZZI CA, PEDROTTI MF, SILVA JS, BARIN JS, NÓBREGA JA AND FLORES EMM. 2017. Microwaveassisted digestion methods: towards greener approaches for plasma-based analytical techniques. J Anal At Spectrom 32: $1448-1466$.

BORDIN DCM, ALVES MNR, DE CAMPOS EG AND DE MARTINIS BS. 2016. Disposable pipette tips extraction: fundamentals, applications and state of the art. J Sep Sci 39: 1168-1172.

BORGES EM, BOTTOLI CBG AND COLLINS CH. 2010. Possibilities and limitations of using temperature in reversed phase liquid chromatography. Quim Nova 33: 945-953.
BORGES SS, FRIZZARIN RM AND REIS BF. 2006. An automatic flow injection analysis procedure for photometric determination of ethanol in red wine without using a chromogenic reagent. Anal Bioanal Chem 385: 197-202.

BRANCALION ML AND ARRUDA MAZ. 2005. Evaluation of medicinal plant decomposition efficiency using microwave ovens and mini-vials for Cd determination by TS-FF-AAS. Microchim Acta 150: 283-290.

BREADMORE MC. 2012. Capillary and microchip electrophoresis: challenging the common conceptions. J Chromatogr A 1221: 42-55.

BRUNETTI AE, MERIB J, CARASEK E, CARAMAO EB, BARBARA J, ZINI CA AND FAIVOVICH J. 2015. Frog volatile compounds: application of in vivo SPME for the characterization of the odorous secretions from two species of Hypsiboas treefrogs. J Chem Ecol 41: 360-372.

BUENO L, COTTELL A, REDDY SM AND PAIXÃO TRLC. 2015a. Coupling dye-integrated polymeric membranes with smartphone detection to classify bacteria. RSC Adv 5: 97962-97965.

BUENO L, MELONI GN, REDDY SM AND PAIXÃO TRLC. 2015b. Use of plastic-based analytical device, smartphone and chemometric tools to discriminate amines. RSC Adv 5: 20148-20154.

CARAMIT RP, LUCCA BG, FERREIRA VS, MUNOZ RAA, RICHTER EM AND DA SILVA RAB. 2015. On-site determination of carbendazim, catechol and hydroquinone in tap water using a homemade batch injection analysis cell for screen printed electrodes. Electroanalysis 27: 271-275.

CASSIANO NM, BARREIRO JC AND CASS QB. 2014. New trends in sample preparation in Brazil: an overview of bioanalytical applications by liquid chromatography. J Braz Chem Soc 25: 9-19.

CELEGHINI RMS, VILEGAS JHY AND LANÇAS FM. 2001. Extraction and quantitative HPLC analysis of coumarin in hydroalcoholic extracts of Mikania glomerata Spreng ("guaco") leaves. J Braz Chem Soc 12: 706-709.

CHAGAS CLS, SOUZA FR, CARDOSO TMG, MOREIRA RC, SILVA JAF, JESUS DP AND COLTRO WKT. 2016. A fully disposable paper-based electrophoresis microchip with integrated pencil-drawn electrodes for contactless conductivity detection. Anal Methods 8: 6682-6686.

CHAVES AR, SILVA BJG, LANÇAS FM AND QUEIROZ MEC. 2011. Biocompatible in-tube solid phase microextraction coupled with liquid chromatographyfluorescence detection for determination of interferon alpha in plasma samples. J Chromatogr A 1218: 33763381.

CHOCHOLOUŠ P, DĚDKOVÁ L, BOHAČOVÁ T, ŠATÍNSKÝ D AND SOLICH P. 2017. Fast separation of red colorants in beverages using cyano monolithic column 
in sequential injection chromatography. Microchem J 130: 384-389

CLARK KD, EMAUS MN, VARONA M, BOWERS AN AND ANDERSON JL. 2018. Ionic liquids: solvents and sorbents in sample preparation. J Sep Sci 41: 209-235.

CODOGNOTO L, ZUIN V, SOUZA D, YARIWAKE JH, MACHADO SAS AND AVACA LA. 2004. Electroanalytical and chromatographic determination of pentachlorophenol and related molecules in a contaminated soil: a real case example. Microchem J 77: 177-184.

COLARES CJG, PASTORE TCM, CORADIN VTR, CAMARGOS JAA, MOREIRA ACO, RUBIM JC AND BRAGA JWB. 2015. Exploratory analysis of the distribution of lignin and cellulose in woods by raman imaging and chemometrics. J Braz Chem Soc 26: 12971305.

COSTA DJE, SANTOS JCS, SANCHES-BRANDÃO FAC, RIBEIRO WF, SALAZAR-BANDA GR AND ARAÚJO MCU. 2017. Boron-doped diamond electrode acting as a voltammetric sensor for the detection of methomyl pesticide. J Electroanal Chem 789: 100-107.

COSTA GB, FERNANDES DDS, ALMEIDA VE, ARAÚJO TSP, MELO JP, DINIZ PHGD AND VÉRAS G. 2015. Digital image-based classification of biodiesel. Talanta 139: 50-55.

COSTARS, SANTOS SRB, ALMEIDALF, NASCIMENTO ECL, PONTES MJC, LIMA RAC, SIMÕES SS AND ARAÚJO MCU. 2004. A novel strategy to verification of adulteration in alcoholic beverages based on Schlieren effect measurements and chemometric techniques. Microchem J 78: 27-33.

DA-COL JA, BUENO MIMS AND MELQUIADES FL. 2015. Fast and direct $\mathrm{Na}$ and $\mathrm{K}$ determination in table, marine, and low-sodium salts by $\mathrm{x}$-ray fluorescence and chemometrics. J Agric Food Chem 63: 2406-2412.

DANCSAK SE, SILVA SG, NÓBREGA JA, JONES BT AND DONATI GL. 2014. Direct determination of sodium, potassium, chromium and vanadium in biodiesel fuel by tungsten coil atomic emission spectrometry. Anal Chim Acta 806: 85-90.

DANIEL D AND GUTZ IGR. 2003. Flow injection spectroelectroanalytical method for the determination of promethazine hydrochloride in pharmaceutical preparations. Anal Chim Acta 494: 215-224.

DANIEL D AND GUTZ IGR. 2007. Microfluidic cell with a $\mathrm{TiO}_{2}$-modified gold electrode irradiated by an UV-LED for in situ photocatalytic decomposition of organic matter and its potentiality for voltammetric analysis of metal ions. Electrochem Commun 9: 522-528.

DANTAS TNC, DANTAS-NETO AA AND MOURA EF. 2001. Microemulsion systems applied to breakdown petroleum emulsions. J Petroleum Sci Eng 32: 145-149.
DE ARAÚJO WR, DE BARROS AV, DE ALMEIDA RM, PANTALEÃO L, BARCELLOS T, SILVA SM AND YONAMINE M. 2015. Determination of low levels of benzodiazepines and their metabolites in urine by hollow-fiber liquid-phase microextraction (LPME) and gas chromatography-mass spectrometry (GC-MS). J Chromatogr B 975: 24-33.

DE ARAÚJO WR, FRASSON CMR, AMEKU WA, SILVA JR, ANGNES L AND PAIXÃO TRLC. 2017. Single-step reagentless laser scribing fabrication of electrochemical paper-based analytical devices. Angew Chem Int Ed Eng 20: 15113-15117.

DE ARAÚJO WR AND PAIXÃO TRLC. 2014. Fabrication of disposable electrochemical devices using silver ink and office paper. Analyst 139: 2742-2747.

DE FARIA LC, PASQUINI C AND OLIVEIRA-NETO G. 1991. Determination of urea in serum by using naturally immobilized urease in a flow injection conductimetric system. Analyst 116: 357-360.

DE FIGUEIREDO-FILHO LCS, BACCARIN M, JANEGITZ BC AND FATIBELLO-FILHO O. 2017. A disposable and inexpensive bismuth film minisensor for a voltammetric determination of diquat and paraquat pesticides in natural water samples. Sensor Actuat B-Chem 240: 749-756.

DE GOIS JS, PEREIRA ER, WELZ B AND BORGES DLG. 2015. Application of direct solid sample analysis for the determination of chlorine in biological materials using electrothermal vaporization inductively coupled plasma mass spectrometry. Spectrochim Acta B 105: 12-17.

DE LIMA CA AND SPINELLI A. 2013. Electrochemical behavior of progesterone at an ex situ bismuth film electrode. Electrochim Acta 107: 542-548.

DESAI R, VILLALBA MM, LAWRENCE NS AND DAVIS J. 2009. Green approaches to field nitrate analysis: an electroanalytical perspective. Electroanalysis 21: 789796.

DINIZ PHGD, ALMEIDA LF, HARDING DP AND ARAÚJO MCU. 2012. Flow-batch analysis. Trend Anal Chem 35: 39-49.

DINIZ PHGD, PISTONESI MF, ARAÚJO MCU AND BAND BSF. 2013. Eco-friendly sonoluminescent determination of free glycerol in biodiesel samples. Talanta 114: 38-42.

DORNELLAS RM, MUNOZ RAA AND AUCELIO RQ. 2015. Electrochemical determination of picoxystrobin on boron-doped diamond electrode: square-wave voltammetry versus BIA-multiple pulse amperometry. Microchem J 123: 1-8.

DOS ANJOS JP AND DE ANDRADE JB. 2014. Determination of nineteen pesticides residues (organophosphates, organochlorine, pyrethroids, 
carbamate, thiocarbamate and strobilurin) in coconut water by SDME/GC-MS. Microchem J 112: 119-126.

FATIBELLO-FILHO O AND VIEIRA IC. 1997. Flow injection spectrophotometric determination of sulfite using crude extract of sweet potato root [Ipomoea batatas (L.) Lam.] as a source of polyphenol oxidase. Anal Chim Acta 354: 51-57.

FAUSTINO N, PINTO PCAG, PASSOS MLC AND SARAIVA MLMFS. 2017. Automatic ionic liquidenhanced membrane microextraction for the determination of melamine in food samples. Food Control 79: 162-168.

FEIGL F. 1955. Organic spot test analysis. Anal Chem 27: 1315-1318.

FERREIRA SLC, MACEDO SM, SANTOS DC, JESUS RM, SANTOS WNL, QUEIROZ AFS AND ANDRADE JB. 2011. Speciation analysis of inorganic antimony in airborne particulate matter employing slurry sampling and HG QT AAS. J Anal At Spectrom 26: 1887-1891.

FILIPPOU O, BITAS D AND SAMANIDOU V. 2017. Green approaches in sample preparation of bioanalytical samples prior to chromatographic analysis. J Chromatogr B 1043: 44-62.

FLORES EMM, SAIDELLES APF, BARIN JS, MORTARI SR AND MARTINS AF. 2001. Hair sample decomposition using polypropylene vials for determination of arsenic by hydride generation atomic absorption spectrometry. J Anal At Spectrom 16: 1419-1423.

FONSECA A, RAIMUNDO JR. IM, ROHWEDDER JJR AND FERREIRA LOS. 2007. Construction and evaluation of a flow injection micro-analyser based on urethane-acrylate resin. Anal Chim Acta 603: 159-166.

FONSECA P AND BONATO PS. 2013. Hollow-fiber liquidphase microextraction and chiral LC-MS/MS analysis of venlafaxine and its metabolites in plasma. Bioanalysis 5: 721-730.

FRANCO MA, ARAÚJO DAG, OLIVEIRA LH, TRINDADE MAG, TAKEUCHI RM AND SANTOS AL. 2016. An amperometric FIA system with carrier recycling: an environmentally friendly approach for atenolol determination in pharmaceutical formulations. Anal Methods 8: 8420-8426.

FREITAS CB, MOREIRA RC, TAVARES MGO AND COLTRO WKT. 2016. Monitoring of nitrite, nitrate, chloride and sulfate in environmental samples using electrophoresis microchips coupled with contactless conductivity detection. Talanta 147: 335-341.

FREITAS-LIMA P, FERREIRA FIS, BERTUCCI C, ALEXANDRE-JUNIOR V, DREOSSI SAC, PEREIRA LRL, SAKAMOTO AC AND QUEIROZ RHC. 2015. Stir bar-sorptive extraction, solid phase extraction and liquid-liquid extraction for levetiracetam determination in human plasma: comparing recovery rates. Braz J Pharm Sci 51: 393-401.
FRIZZARIN RM AND ROCHA FRP. 2014. An improved approach for flow-based cloud point extraction. Anal Chim Acta 820: 69-75.

FU G, HE Y, YU C, GAO Y AND GAN W. 2009. Preconcentration and determination of carbamate pesticide residues in vegetable samples by electrokinetic flow analysis with on-line hollow fiber liquid-liquid-liquid microextraction and spectrophotometry. Spect Letters 42: 305-311.

FUMES BH AND LANÇAS FM. 2017. Use of graphene supported on aminopropyl silica for microextraction of parabens from water samples. J Chromatogr A 1487: 6471.

FUMES BH, SILVA MR, ANDRADE FN, NAZARIO CED AND LANÇAS FM. 2015. Recent advances and future trends in new materials for sample preparation. Trend Anal Chem 71: 9-25.

FUNARI CS, CARNEIRO RL, ANDRADE AM, HILDER EF AND CAVALHEIRO AJ. 2014. Green chromatographic fingerprinting: An environmentally friendly approach for the development of separation methods for fingerprinting complex matrices. J Sep Sci 37: $37-44$

FURUSAWA N AND TSUMATANI E. 2012. "Green" HPLC with $100 \%$ water eluent for analysing melamine in milk. LC GC Eur 25: 292-298.

GABRIEL EFM, GARCIA PT, CARDOSO TMG, LOPES FM, MARTINS FT AND COLTRO WKT. 2016. Highly sensitive colorimetric detection of glucose and uric acid in biological fluids using chitosan-modified paper microfluidic devices. Analyst 141: 4749-4756.

GAŁUSZKA A, ZDZISŁAW M AND NAMIESNIK J. 2013. The 12 principles of green analytical chemistry and the SIGNIFICANCE mnemonic of green analytical practices. Trend Anal Chem: 78-84.

GAMA MR, AGGARWAL P, LEE ML AND BOTTOLI CBG. 2017. Controlled crosslinking of trimethylolpropane trimethacrylate for preparation of organic monolithic columns for capillary liquid chromatography. Electrophoresis 38: 3029-3035.

GAMA MR, COLLINS CH AND BOTTOLI CBG. 2013. Nano-liquid chromatography in pharmaceutical and biomedical research. J Chromatogr Sci 51: 694-703.

GARRIGUES S AND DE LA GUARDIA M. 2013. Noninvasive analysis of solid samples. Trends Anal Chem 43: 161-173.

GERENT GG, GONÇALVES CQ, DA SILVA PS, SPINELLI A. 2015. In situ bismuth-film electrode for square-wave cathodic voltammetric detection of pendimethalin at nanomolar level. Electrochim Acta 168: 379-385.

GONZÁLES APS, FIRMINO MA, NOMURA CS, ROCHA FRP, OLIVEIRA PV AND GAUBEUR I. 2009. Peat 
as a natural solid-phase for copper preconcentration and determination in a multicommuted flow system coupled to flame atomic absorption spectrometry. Anal Chim Acta 636: 198-204.

GRILO AL, AIRES-BARROS MR AND AZEVEDO AM. 2016. Partitioning in aqueous two-phase systems: fundamentals, applications and trends. Sep Purif Rev 45: 68-80.

GUERRA MBB, ADAME A, ALMEIDA E, CARVALHO GGA, BRASIL MAS, SANTOS JR D AND KRUG FJ. 2015. Direct analysis of plant leaves by EDXRF and LIBS: microsampling strategies and cross-validation. J Anal At Spectrom 30: 1646-1654.

HANTAO LW, ALEME HG, PASSADOR MM, FURTADO EL, RIBEIRO FAD, POPPI RJ AND AUGUSTO F. 2013. Determination of disease biomarkers in Eucalyptus by comprehensive two-dimensional gas chromatography and multivariate data analysis. J Chromatogr A 1279: 8691.

HELFER GA, MAGNUS VS, BÖCK FC, TEICHMANN A, FERRÃO MF AND COSTA AB. 2016. PhotoMetrix: an application for univariate calibration and principal components analysis using colorimetry on mobile devices. J Braz Chem Soc 28: 328-335.

HOCEVAR L, SOARES VRB, OLIVEIRA FS, KORN MGA AND TEIXEIRA LSG. 2012. Application of multivariate analysis in Mid-infrared spectroscopy as a tool for the evaluation of waste frying oil blends. J Am Oil Chem Soc 89: 781-786.

INTIMA DP, OLIVEIRA E AND OLIVEIRA PV. 2009. Feasibility of using in situ fusion for the determination of $\mathrm{Co}, \mathrm{Cr}$ and $\mathrm{Mn}$ in Portland cement by direct solid sampling graphite furnace atomic absorption spectrometry. Spectrochim Acta Part B 64: 610-614.

IQBAL M ET AL. 2016. Aqueous two-phase system (ATPS): an overview and advances in its applications. Biol Proced Online 18: 18.

JIA MY, WU QS, LI H, ZHANG Y, GUAN YF AND FENG L. 2015. The calibration of cellphone camerabased colorimetric sensor array and its application in the determination of glucose in urine. Biosens Bioelectron 74: 1029-1037.

JOHANSSON HO, PERSSON J AND TJERNELD F. 1999. Thermoseparating water/polymer system: a novel one-polymer aqueous two-phase system for protein purification. Biotechnol Bioeng 66: 247-257.

JOST CL, DI MARTOS LM, FERRAZ L AND DO NASCIMENTO PC. 2016. Sequential voltammetric determination of uranium, cadmium and lead by using the ex situ bismuth film electrode: application to phosphate fertilizers. Electroanalysis 28: 287-295.

KABIR A, LOCATELLI M AND ULUSOY HI. 2017. Recent trends in microextraction techniques employed in analytical and bioanalytical sample preparation. Separation $4: 36$.

KALJURAND M AND KOEL M. 2011. Recent advancements on greening analytical separation, Crit Rev Anal Chem 41: 2-20.

KOCUROVA L, BALOGH IS AND ANDRUCH V. 2013. Solvent microextraction: a review of recent efforts at automation. Microchem J 110: 599-607.

KOUDELKA-HEP M AND VAN DER WAL PD. 2000. Microelectrode sensors for biomedical and environmental applications. Electrochim Acta 45: 2437-2441.

KRUG FJ, BERGAMIN-FILHO H, ZAGATTO EAG AND JORGENSEN SS. 1977. Rapid determination of sulphate in natural waters and plant digests by continuous flow injection turbidimetry. Analyst 102: 503-508.

LANÇAS FM, QUEIROZ MEC, GROSSI P AND OLIVARES IRB. 2009. Recent developments and applications of stir bar sorptive extraction. J Sep Sci 32: 813-824.

LAPA RAS, LIMA JLFC, REIS BF, SANTOS JLM AND ZAGATTO EAG. 2002. Multi-pumping in flow analysis: concepts, instrumentation, potentialities. Anal Chim Acta 466: $125-132$.

LESELLIER E AND WEST C. 2015. The many faces of packed column supercritical fluid chromatography - a critical review. J Chromatogr A 1382: 2-46.

LEZI N AND ECONOMOU A. 2015. Voltammetric determination of neonicotinoid pesticides at disposable screen-printed sensors featuring a sputtered bismuth electrode. Electroanalysis 27: 2313-2321.

LEZI N, ECONOMOU A, BAREK J AND PRODROMIDIS M. 2014. Screen-printed disposable sensors modified with bismuth precursors for rapid voltammetric determination of 3 ecotoxic nitrophenols. Electroanalysis 26: 766-775.

LIMBECK A, BONTA M AND NISCHKAUER W. 2017. Improvements in the direct analysis of advanced materials using ICP-based measurement techniques. J Anal At Spectrom 32: 212-232.

LOWINSOHN D, RICHTER EM, ANGNES L AND BERTOTTI M. 2006. Disposable gold electrodes with reproducible area using recordable CDs and toner masks. Electroanalysis 18: 89-94.

LUIZ VHM, PEZZA L AND PEZZA HR. 2013. Rapid determination of furosemide by combined spot test/ diffuse reflectance spectroscopy to detect doping in sport. Microchem J 109: 68-72.

MAHDI-MOEIN M, ABDEL-REHIM A AND ABDELREHIM M. 2015. Microextraction by packed sorbent (MEPS). TrAC - Trend Anal Chem 67: 34-44.

MAHDI-MOEIN M, SAID R, BASSYOUNI F AND ABDEL-REHIM M. 2014. Solid phase microextraction and related techniques for drugs in biological samples. J Anal Met Chem 2014: 921350. 
MAJORS RE. 2000. Stationary-phase technology in separation science. LC GC N Am 18: 1214-1227.

MARQUES EJN, FREITAS ST, PIMENTEL MF AND PASQUINI C. 2016. Rapid and non-destructive determination of quality parameters in the 'Tommy Atkins' mango using a novel handheld near infrared spectrometer. Food Chem 197: 1207-1214.

MARTINEZ AW, PHILLIPS ST, BUTTE MJ AND WHITESIDES GM. 2007. Patterned paper as a platform for inexpensive, low-volume, portable bioassays. Angew Chemie Int Ed 46: 1318-1320.

MELCHERT WR AND ROCHA FRP. 2005. A green analytical procedure for flow-injection determination of nitrate in natural waters. Talanta 65: 461-465.

MELCHERT WR AND ROCHA FRP. 2016. Cloud point extraction in flow-based systems. Anal Chem 35: 41-53.

MELCHERT WR, REIS BF AND ROCHA FRP. 2012. Green chemistry and the evolution of flow analysis. A review. Anal Chim Acta 714: 8-19.

MENDES G, ALEME HG AND BARBEIRA PJS. 2012. Determination of octane numbers in gasoline by distillation curves and partial least squares regression. Fuel 97: 131136.

MERIB J, YU H, CARASEK E AND ANDERSON JL. 2016. Determination of compounds with varied volatilities from aqueous samples using a polymeric ionic liquid sorbent coating by direct immersion-headspace solidphase microextraction. Anal Methods 8: 4108-4118.

MESKO MF, PEREIRA JSF, MORAES DP, BARIN JS, MELLO PA, PANIZ JNG, NÓBREGA JA, KORN MGA AND FLORES EMM. 2010. Focused microwaveinduced combustion: a new technique for sample digestion. Anal Chem 82: 2155-2160.

METTAKOONPITAK J, BOEHLE K, NANTAPHOL S, TEENGAM P, ADKINS JA, SRISA-ART M AND HENRY CS. 2016. Electrochemistry on paper-based analytical devices: A review. Electroanalysis 28: 14201436.

MIRÓ M AND HANSEN EH. 2013. On-line sample processing involving microextraction techniques as a front-end to atomic spectrometric detection for trace metal assays: A review. Anal Chim Acta 782: 1- 11.

MONTE-FILHO SS, LIMA MB, ANDRADE SIE, HARDING DP, FAGUNDES YNM, SANTOS SRB, LEMOS SG AND ARAÚJO MCU. 2011. Flow-batch miniaturization. Talanta 86: 208-213.

MORAES DP, MESKO MF, MELLO PA, PANIZ JNG, DRESSLER VL, KNAPP G AND FLORES EMM. 2007. Application of microwave induced combustion in closed vessels for carbon black-containing elastomers decomposition. Spectrochim Acta Part B 62: 1065-1071.

MORBIOLI GG, NASCIMENTO TM, STOCKTON AM AND CARRILHO E. 2017. Technical aspects and challenges of colorimetric detection with microfluidic paper-based analytical devices (mPADs) - a review. Anal Chim Acta 970: 1-22.

NASCENTES CC, KORN M AND ARRUDA MAZ. 2001. A fast ultrasound-assisted extraction of $\mathrm{Ca}, \mathrm{Mg}, \mathrm{Mn}$, and Zn from vegetables. Microchem J 69: 37-43.

NASCIMENTO CF, ROCHA DL AND ROCHA FRP. 2015. A fast and environmental friendly analytical procedure for determination of melamine in milk exploiting fluorescence quenching. Food Chem 169: 314-319.

NASCIMENTO TM, LEÃO PAGC, CATAI JR, MORBIOLI GG AND CARRILHO E. 2016. Towards low-cost bioanalytical tools for sarcosine assays for cancer diagnostics. Anal Methods 8: 7312-7318.

NAZARIO CED, SILVA MR, FRANCO MS AND LANÇAS FM. 2015. Evolution in miniaturized column liquid chromatography instrumentation and applications: an overview. J Chromatogr A 1421: 18-37.

NEEDHAM SR. 2017. Microspray and microflow liquid chromatography: the way forward for LC-MS bioanalysis. Bioanalysis 9: 1935-1937.

NERIN C. 2016. Basic principles and applications of liquid phase microextraction techniques. Sci Chromatogr 8: 137 142.

NIU JC, ZHOU T, NIU LL, XIE ZS, FANG F, YANG FQ AND WU ZY. 2018. Simultaneous pre-concentration and separation on simple paper-based analytical device for protein analysis. Anal Bioanal Chem 410: 1689-1695.

NOMURA CS AND OLIVEIRA PV. 2010. Method for cadmium and lead longitudinal profiles determination in hair by solid sampling graphite furnace atomic absorption spectrometry. Anal Methods 2: 49-53.

OCHIAI LM, AGUSTINI D, FIGUEIREDO-FILHO LCS, BANKS CE, MARCOLINO-JUNIOR LH AND BERGAMINI MF. 2017. Electroanalytical thread-device for estriol determination using screen-printed carbon electrodes modified with carbon nanotubes. Sensor Actuat B-Chem 241: 978-984.

OJEDA CB AND ROJAS FS. 2004. Recent developments in derivative ultraviolet/visible absorption spectrophotometry. Anal Chim Acta 518: 1-24.

OLIVEIRA AS, DALLA-NORA FM, MELLO RO, MELLO PA, TISCHER B, COSTA AB AND BARIN JS. 2017. One-Shot, reagent-free determination of the alcoholic content of distilled beverages by thermal infrared enthalpimetry. Talanta 171: 335-340.

ORTEGA SN, SANTOS-NETO AJ AND LANÇAS FM. 2017. Development and optimization of a fast method for the determination of statins in human plasma using microextraction by packed sorbent (MEPS) followed by ultra high-performance liquid chromatography-tandem mass spectrometry (UHPLC-MS/MS). Anal Methods 9: 3039-3048. 
OSORIO ACP, CUNHA ALMC, KHAN S, FRANCO CJ, PEREIRA-NETTO AD AND AUCÉLIO RQ. 2014. Photochemical derivatization of amitriptyline using a green chemistry approach: fluorimetric determination and photochemical reaction mechanism. Anal Methods 6: 4022-4028.

PAIVA MJN, MENEZES HC, SILVA JCC, RESENDE RR AND CARDEAL ZL. 2015. New method for the determination of bile acids in human plasma by liquidphase microextraction using liquid chromatography-iontrap-time-of-flight mass spectrometry. J Chromatogr A 1388: 102-109.

PAIXÃO TRLC, CARDOSO JL AND BERTOTTI M. 2007. Determination of nitrate in mineral water and sausage samples by using a renewable in situ copper modified electrode. Talanta 71: 186-191.

PASQUINI C AND OLIVEIRA WA. 1985. Monosegmented system for continuous-flow analysis-spectrophotometric determination of chromium(VI), ammonia, and phosphorus. Anal Chem 57: 2575-2579.

PAULO JM, MENDES G, BARROS JE AND BARBEIRA PJ. 2012. A study of adulteration in gasoline samples using flame emission spectroscopy and chemometrics tools. Analyst 137: 5919-5924.

PEDROSA VA, CAETANO J, MACHADO SAS AND BERTOTTI M. 2008. Determination of parathion and carbaryl pesticides in water and food samples using a self assembled monolayer /acetylcholinesterase electrochemical biosensor. Sensors 8: 4600-4610.

PEGO AMF, ROVERI FL, KUNINARI RY, LEYTON V, MIZIARA ID AND YONAMINE M. 2017. Determination of cocaine and its derivatives in hair samples by liquid phase microextraction (LPME) and gas chromatography-mass spectrometry (GC-MS). Forensic Sci Int 274: 83-90.

PEREIRA AC AND ROCHA FRP. 2013. A multicommuted flow system with liquid-liquid microextraction for determination of anionic surfactants in freshwaters. Anal Methods 5: 2104-2109.

PEREIRA CAM, RODRIGUES TR AND YARIWAKE JH. 2014a. Quantification of harman alkaloids in sour passion fruit pulp and seeds by a novel dual SBSE-LC/Flu (stir bar sorptive extraction-liquid chromatography with fluorescence detector) method. J Braz Chem Soc 25: 14721483.

PEREIRA FM, BRUM DM, LEPRI FG AND CASSELLA RJ. 2014b. Extraction induced by emulsion breaking as a tool for $\mathrm{Ca}$ and $\mathrm{Mg}$ determination in biodiesel by fast sequential flame atomic absorption spectrometry (FSFAAS) using Co as internal standard. Microchem J 117: 172-177.

PEREIRA FM, ZIMPECK RC, BRUM DM AND CASSELLA RJ. 2013b. Novel extraction induced by emulsion breaking as a tool for the determination of trace concentrations of $\mathrm{Cu}, \mathrm{Mn}$ and $\mathrm{Ni}$ in biodiesel by electrothermal atomic absorption spectrometry. Talanta 117: 32-38.

PEREIRA JSF, PICOLOTO RS, PEREIRA LSF, GUIMARAES RCL, GUARNIERI RA AND FLORES EMM. 2013a. High-efficiency microwave-assisted digestion combined to in situ ultraviolet radiation for the determination of rare earth elements by ultrasonic nebulization ICPMS in crude oils. Anal Chem 85: 1103411040.

PESSOA GD, LOPES CA, MADRID KC AND ARRUDA MAZ. 2017. A quantitative approach for $\mathrm{Cd}, \mathrm{Cu}, \mathrm{Fe}$ and Mn through laser ablation imaging for evaluating the translocation and accumulation of metals in sunflower seeds. Talanta 167: 317-324.

PIMENTEL MF, RIBEIRO GMGS, CRUZ RS, STRAGEVITCH L, PACHECO-FILHO JGA AND TEIXEIRA LSG. 2006. Determination of biodiesel content when blended with mineral diesel fuel using infrared spectroscopy and multivariate calibration. Microchem J 82: 201-206.

PINTO IP AND PEDROSO MP. 2015. Single drop microextraction (SDME): fundamentals and applications. Sci Chromatogr 7: 183-198.

PIRI-MOGHADAM H, ALAM MN AND PAWLISZYN J. 2017. Review of geometries and coating materials in solid phase microextraction: opportunities, limitations, and future perspectives. Anal Chim Acta 984: 42-65.

PLOTKA-WASYLKA J, RUTKOWSKA M, OWCZAREK K, TOBISZEWSKI M AND NAMIESNIK J. 2017. Extraction with environmentally friendly solvents. Trend Anal Chem 91: 12-25.

PRIEN R, PASCAL R, MOWLEM M, DENUAULT G AND SOSNA M. 2005. Development and first results of a new fast response microelectrode DO-sensor. OceansEurope 1: 744-747.

QUEIROZ MEC. 2011. Microextração em sorvente empacotado (MEPS) para a determinação de fármacos em fluidos biológicos. Sci Chromatogr 3: 223-229.

QUEIROZ MEC, OLIVEIRA EB, BRETON F AND PAWLISZYN J. 2007. Immunoaffinity in-tube solid phase microextraction coupled with liquid chromatography-mass spectrometry for analysis of fluoxetine in serum samples. J Chromatogr A 1174: 72-77.

RADJENOVIC J AND SEDLAK DL. 2015. Challenges and opportunities for electrochemical processes as nextgeneration technologies for the treatment of contaminated water. Environ Sci Technol 49: 11292-11302.

REIS BF, GINÉ MF, ZAGATTO EAG, LIMA JLFC AND LAPA RA. 1994. Multicommutation in flow-analysis. 1. Binary sampling-concepts, instrumentation and 
spectrophotometric determination of iron in plant digests. Anal Chim Acta 293: 129-138.

RESENDE LV AND NASCENTES CC. 2016. A simple method for the multi-elemental analysis of organic fertilizer by slurry sampling and total reflection X-ray fluorescence. Talanta 147: 485-492.

RIBEIRO RLV, BOTTOLI CBG, COLLINS KE AND COLLINS CH. 2004. Reevaluation of ethanol as organic modifier for use in HPLC-RP mobile phases. J Braz Chem Soc 15: 300-306.

RIVELLINO SR, HANTAO LW, RISTICEVIC S, CARASEK E, PAWLISZYN J AND AUGUSTO F. 2013. Detection of extraction artifacts in the analysis of honey volatiles using comprehensive two-dimensional gas chromatography. Food Chem 141: 1828-1833.

ROBAINA NF, FEITEIRA FN, CASSELLA AR AND CASSELLA RJ. 2016. Determination of chloride in brazilian crude oils by ion chromatography after extraction induced by emulsion breaking. J Chromatogr A 1458: 112117.

ROCHA DL, BATISTA AD, ROCHA FRP, DONATI DL AND NÓBREGA JA. 2013. Greening sample preparation in inorganic analysis. Trend Anal Chem 45: 79-92.

ROCHA DL AND ROCHA FRP. 2013. Photochemical microdigestion in a multi-pumping flow system for phosphorus fractionation in cereals. Microchem J 109: 139-144.

ROCHA FRP, TEIXEIRA LSG AND NÓBREGA JA. 2009. Green strategies in trace analysis: a glimpse of simple alternatives for sample pretreatment and analyte determination. Spectrosc Lett 42: 418-429.

RODA A, MICHELINI E, ZANGHERI M, DI FUSCO M, CALABRIA D AND SIMONI P. 2016. Smartphonebased biosensors: a critical review and perspectives. Trend Anal Chem 79: 317-325.

RODRIGUES GD, LEMOS LR, SILVA LHM AND SILVA MCH. 2012. Monosegmented flow analysis exploiting aqueous two-phase systems for the determination of cobalt. Anal Sci 28: 1213-1218.

RODRIGUES GD, SILVA LHM AND SILVA MCH. 2010. Alternativas verdes para o preparo de amostra e determinação de poluentes fenólicos em água. Quim Nova 33: $1370-1378$

RUZICKA J AND MARSHALL GD. 1990. Sequential injection: a new concept for chemical sensors, process analysis and laboratory assays. Anal Chim Acta 237: 329343.

SAMPAIOTRANDFONSECAA. 2015. Chemiluminescence detection in urethane-acrylate microfluidic devices. Sensor Actuat B-Chem 213: 215-221.

SANDRA P, DAVID F, PEREIRA A, DUNKLE M AND BRUNELLI C. 2010. Green chromatography (part 2): the role of GC and SFC. LC GC Eur 23: 396-405.
SANTHIAGO M, HENRY CS AND KUBOTA LT. 2014. Low cost, simple three dimensional electrochemical paperbased analytical device for determination of p-nitrophenol. Electrochim Acta 130: 771-777.

SANTOS JR D, KRUG FJ, PEREIRA MG AND KORN M. 2006. Currents on ultrasound-assisted extraction for sample preparation and spectroscopic analytes determination. Appl Spectrosc Rev 41: 305-321.

SANTOS PM, PEREIRA-FILHO ER AND RODRIGUEZSAONA LE. 2013. Rapid detection and quantification of milk adulteration using infrared microspectroscopy and chemometrics analysis. Food Chem 138: 19-24.

SARAFRAZ-YAZDI A AND RAZAVI N. 2015. Application of molecularly-imprinted polymers in solid-phase microextraction techniques. Trend Anal Chem 75: 81-90.

SCHACKER RL, MORITZ DE, CARO MSB, MADUREIRA LAS, DIAS NA, MERIB JO, ISFRAN D AND CARASEK E. 2017. Study of viability of solid-phase microextraction, in vivo, in the extraction of microbial volatile organic compounds associated to the pigment production process by the Monascus fungus, in submerged fermentation. J Braz Chem Soc 28: 1113-1122.

SCHEFFLER GL, DRESSLER VL AND POZEBON D. 2014. Rice slurry analysis using mixed-gas plasma and axially viewed ICP OES. Food Anal Method 7: 1415-1423.

SELVA TMG AND PAIXÃO TRLC. 2016a. Electrochemical quantification of propoxur using a boron-doped diamond electrode. Diam Relat Mater 66: 113-118.

SELVA TMG AND PAIXÃO TRLC. 2016b. Boron-doped diamond as a sensor for the classification of carbamate pesticides using a chemometric approach. New J Chem 40: 2514-2520.

SHANGGUAN XD, TANG HS, LIU RX AND ZHENG JB. 2010. Ionic liquids and its application in electroanalytical chemistry. Chin J Anal Chem 38: 1510-1516.

SHIMAMOTO GG, TERRA J AND BUENO MIMS. 2013. Use of portable X-ray fluorescence to discriminate brands of nail polishes: a potential forensic tool. J Braz Chem Soc 24: 731-735.

SILVA IS, DE ARAUJO WR, PAIXÃO TRLC AND ANGNES L. 2013. Direct nitrate sensing in water using an array of copper-microelectrodes from flat flexible cables. Sensor Actuat B-Chem 188: 94-98.

SILVA LAJ, DA SILVA WP, GIULIANI JG, CANOBRE SC, GARCIA CD, MUNOZ RAA AND RICHTER EM. 2017. Use of pyrolyzed paper as disposable substrates for voltammetric determination of trace metals. Talanta 165 : 33-38.

SILVA LHM AND LOH W. 2006. Sistemas aquosos bifásicos: fundamentos e aplicações para partição/purificação de proteínas. Quim Nova 29: 1345-1351.

SILVA RCS, MANO V, PEREIRA AC, FIGUEIREDO EC AND BORGES KB. 2016a. Development of pipette tip- 
based on molecularly imprinted polymer micro-solid phase extraction for selective enantioselective determination of $(-)-(2 \mathrm{~S}, 4 \mathrm{R})$ and $(+)-(2 \mathrm{R}, 4 \mathrm{~S})$ ketoconazole in human urine samples prior to HPLC-DAD. Anal Methods 8: 4075-4085.

SILVA SG, OLIVEIRA PV AND ROCHA FRP. 2010. A green analytical procedure for determination of copper and iron in plant materials after cloud point extraction. J Braz Chem Soc 21: 234-239.

SILVA TG, DE ARAUJO WR, MUNOZ RAA, RICHTER EM, SANTANA MHP, COLTRO WKT AND PAIXÃO TRLC. 2016b. Simple and sensitive paper-based device coupling electrochemical sample pretreatment and colorimetric detection. Anal Chem 88: 5145-5151.

SILVEIRA GO, BELITSKY IT, LODDI S, OLIVEIRA CDR, ZUCOLOTO AD, FRUCHTENGARTEN LVG AND YONAMINE M. 2016. Development of a method for the determination of cocaine, cocaethylene and norcocaine in human breast milk using liquid phase microextraction and gas chromatography-mass spectrometry. Forensic Sci Int 265: 22-28.

SIMÕES FR, VAZ CMP AND BRETT CMA. 2007. Electroanalytical detection of the pesticide paraquat by batch injection analysis. Anal Lett 40: 1800-1810.

SOARES RD, WELKE JE, NICOLLI KP, ZANUS M, CARAMAO EB, MANFROI V AND ZINI CA. 2015. Monitoring the evolution of volatile compounds using gas chromatography during the stages of production of Moscatel sparkling wine. Food Chem 183: 291-304.

SOARES S, LIMA MJA AND ROCHA FRP. 2017. A spot test for iodine value determination in biodiesel based on digital images exploiting a smartphone. Microchem J 133: 195-199.

SOUZA AL, SILVA FF, KELMER GAR AND OLIVEIRA PV. 2013. A green method for the simultaneous determination of $\mathrm{Cd}$ and $\mathrm{Pb}$ in soil and sediment by slurry sampling graphite furnace atomic absorption spectrometry. Anal Methods 5: 2059-2063.

SOUZA ID, DOMINGUES DS AND QUEIROZ MEC. 2015. Hybrid silica monolith for microextraction by packed sorbent to determine drugs from plasma samples by liquid chromatography-tandem mass spectrometry. Talanta 140: 166-175.

SOUZA ID, MELO LP, JARDIM ICSF, MONTEIRO JCS, NAKANO MAS AND QUEIROZ MEC. 2016. Selective molecularly imprinted polymer combined with restricted access material for in-tube SPME/UHPLC-MS/MS of parabens in breast milk samples. Anal Chim Acta 932: 4959.

SOUZA-SILVA E, RISTICEVIC S AND PAWLISZYN J. 2013. Recent trends in SPME concerning sorbent materials, configurations and in vivo applications. Trend Anal Chem 43: 24-36.
SPERLING KR. 1984. Determination of Cd traces in environmental samples. In: Fortschritte in der Atomspektrometrischen Spurenanalytik, v. 2, Weinheim: Wiley-VCH, p. 385-401.

ŠTĚPÁNOVÁ S AND KAŠIČKA V. 2017. Analysis of proteins and peptides by electromigration methods in microchips. J Sep Sci 40: 228-250.

SUFFREDINI HB, PEDROSA VA, CODOGNOTO L, MACHADO SAS, ROCHA-FILHO RC AND AVACA LA. 2004. Enhanced electrochemical response of borondoped diamond electrodes brought on by a cathodic surface pre-treatment. Electrochim Acta 49: 4021-4026.

TAI C, JIANG S AND SAHAYAM AC. 2016. Determination of $\mathrm{As}, \mathrm{Hg}$ and $\mathrm{Pb}$ in herbs using slurry sampling flow injection chemical vapor generation inductively coupled plasma mass spectrometry. Food Chem 192: 274-279.

TAO Y, ZHEN Z, YU Y, XU J, LIU X, WU X, DONG F AND ZHENG Y. 2018. Supercritical fluid chromatographytandem mass spectrometry-assisted methodology for rapid enantiomeric analysis of fenbuconazole and its chiral metabolites in fruits, vegetables, cereals, and soil. Food Chem 241: 32-39.

TAVARES MCH, VILEGAS JHY AND LANÇAS FM. 2001. Separation of underivatised triterpene acids by capillary supercritical fluid chromatography. Phytochem Anal 12: 134-137.

TEIXEIRA LSG AND ROCHA FRP. 2007. A green analytical procedure for sensitive and selective determination of iron in water samples by flow-injection solid-phase spectrophotometry. Talanta 71: 1507-1511.

TOLEDO BR, HANTAO LW, HO TD, AUGUSTO F AND ANDERSON JL. 2014. A chemometric approach toward the detection and quantification of coffee adulteration by solid-phase microextraction using polymeric ionic liquid sorbent coatings. J Chromatogr A 1346: 1-7.

TOTOLI EG AND SALGADO HRN. 2015. Development, optimization, and validation of a green and stabilityindicating HPLC method for determination of daptomycin in lyophilized powder. J AOAC Int 98: 1276-1285.

TREVELIN AM, MAROTTO RES, CASTRO EVR, BRANDAO GP, CASSELLA RJ AND CARNEIRO MTWD. 2016. Extraction induced by emulsion breaking for determination of $\mathrm{Ba}, \mathrm{Ca}, \mathrm{Mg}$ and $\mathrm{Na}$ in crude oil by inductively coupled plasma optical emission spectrometry. Microchem J 124: 338-343.

TROJANOWICZ M AND KOŁACINSKA K. 2016. Recent advances in flow injection analysis. Analyst 141: 20852139.

TSUDA T AND HUSSEY CL. 2007. Electrochemical applications of room-temperature ionic liquids. Electrochem Soc Interface 16:42-49.

TURNER C. 2013. Sustainable analytical chemistry-more than just being green. Pure Appl Chem 85: 2217-2229. 
VAKH C, POCHIVALOV A, ANDRUCH V AND MOSKVIN L. 2016. A fully automated effervescenceassisted switchable solvent-based liquid phase microextraction procedure: liquid chromatographic determination of ofloxacin in human urine samples. Anal Chim Acta 907: 54-59.

VANHOENACKER G, SANDRA P, DAVID F, SANDRA K AND PEREIRA A. 2010. Green chromatography (part 1): introduction and liquid chromatography. LC GC Eur 23: 242-259.

VASCONCELOS EC, VILEGAS JHY AND LANÇAS FM. 2000. Comparison of extraction and clean-up methods for the analysis of friedelan-3-ol and friedelin from leaves of Maytenus aquifolium Martius (Celastraceae). Phytochem Anal 11: 247-250.

VIANA IMD, LIMA PDR, SOARES CDV AND FERNANDES C. 2014. Simultaneous determination of oral antidiabetic drugs in human plasma using microextraction by packed sorbent and high-performance liquid chromatography. J Pharm Biom Anal 96: 241-248.

VICENTINO PO AND CASSELLA RJ. 2017. Novel extraction induced by microemulsion breaking: a model study for $\mathrm{Hg}$ extraction from Brazilian gasoline. Talanta 162: 249-255.

VIEIRA IC AND FATIBELLO-FILHO O. 1998. Flow injection spectrophotometric determination of total phenols using a crude extract of sweet potato root [Ipomoea batatas (L.) Lam.] as enzymatic source. Anal Chim Acta 366: 111-118.

VIEIRA IC, LUPETTI KO, FATIBELLO-FILHO O. 2003. Determination of paracetamol in pharmaceutical products using a carbon paste biosensor modified with crude extract of zucchini (Cucurbita pepo). Quim Nova 26: 39-43.

VILEGAS JHY, LANÇAS FM, VILEGAS W AND POZETTI GL. 1993. Off-line supercritical-fluid extraction - high-resolution gas-chromatography applied to the study of Moraceae species. Phytochem Anal 4: 230-234.

VLASOVY, LEGINA, RUDNITSKAYAAAND D'AMICO A. 2005. Nonspecific sensor arrays ("electronic tongue") for chemical analysis of liquids (IUPAC Technical Report). Pure Appl Chem 77: 1965-1983.

WANG J, FOSTER N, ARMALIS S, LARSON D, ZIRINO A AND OLSEN K. 1995. Remote stripping electrode for in situ monitoring of labile copper in the marine environment. Anal Chim Acta 310: 223-231.

WANG J AND HANSEN EH. 2003. Sequential injection labon-valve: the third generation of flow injection analysis. Trends Anal Chem 22: 225-231.

WANG J AND TAHA Z. 1991. Batch injection analysis. Anal Chem 63: 1053-1056.

WELCH CJ ET AL. 2010. Greening analytical chromatography. TrAC - Trend Anal Chem 29: 667-680.

WELLER A, CARRASCO-CORREA EJ, BELENGUERSAPINA C, MAURI-AUCEJO AD, AMOROS P AND HERRERO-MARTINEZ JM. 2017. Organo-silica hybrid capillary monolithic column with mesoporous silica particles for separation of small aromatic molecules. Microchim Acta 184: 3799-3808.

YANG K, PERETZ-SOROKA H, LIU Y AND LIN F. 2016. Novel developments in mobile sensing based on the integration of microfluidic devices and smartphones. Lab Chip 16: 943-958.

YANG Y, NGUYEN MP, GEISS BJ, DANDY DS AND HENRY CS. 2017. Paper-based microfluidic devices: emerging themes and applications. Anal Chem 89: 71-91.

YEUNG LWY, STADEY C AND MABURY SA. 2017. Simultaneous analysis of perfluoroalkyl and polyfluoroalkyl substances including ultrashort-chain $\mathrm{C} 2$ and $\mathrm{C} 3$ compounds in rain and river water samples by ultra performance convergence chromatography. J Chromatogr A 1522: 78-85.

ZAGATTO EAG, JACINTHO AO, MORTATTI J AND BERGAMIN-FILHO H. 1980. An improved flow injection determination of nitrite in waters by using intermittent flows. Anal Chim Acta 120: 399-403.

ZASLAVSKY BY. 1995. Aqueous two-phase partitioning: physical chemistry and bioanalytical applications. New York: Marcel Dekker, 696p.

ZHANG D AND LIU Q. 2016. Biosensors and bioelectronics on smartphone for portable biochemical detection. Biosens Bioelectron 75: 273-284.

ZWEIG A. 1973. Photochemical generation of stable fluorescent compounds (photofluorescence). Pure Appl Chem 33: 389-410. 